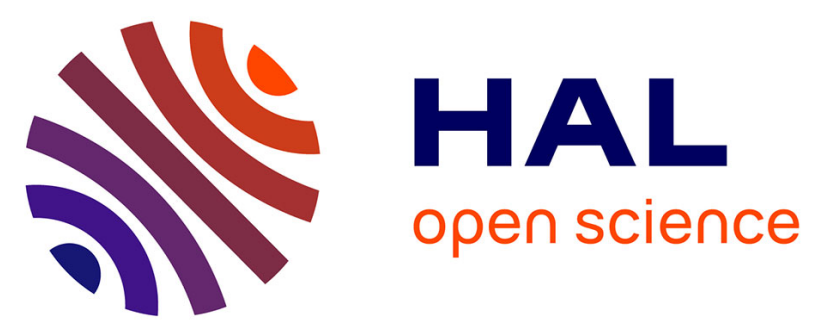

\title{
Synthesis and biological evaluation of new naphtho- and quinolinocyclopentane derivatives as potent melatoninergic (MT 1 /MT 2 ) and serotoninergic (5-HT 2C ) dual ligands
}

Romain Duroux, Marouan Rami, Elodie Landagaray, Mohamed Ettaoussi, Daniel-Henri Caignard, Philippe Delagrange, Patricia Melnyk, Saïd Yous

\section{To cite this version:}

Romain Duroux, Marouan Rami, Elodie Landagaray, Mohamed Ettaoussi, Daniel-Henri Caignard, et al.. Synthesis and biological evaluation of new naphtho- and quinolinocyclopentane derivatives as potent melatoninergic (MT 1 /MT 2 ) and serotoninergic (5-HT 2C ) dual ligands. European Journal of Medicinal Chemistry, 2017, 141, pp.552-566. 10.1016/j.ejmech.2017.10.025 . hal-02011786

\author{
HAL Id: hal-02011786 \\ https://hal.science/hal-02011786
}

Submitted on 7 Mar 2019

HAL is a multi-disciplinary open access archive for the deposit and dissemination of scientific research documents, whether they are published or not. The documents may come from teaching and research institutions in France or abroad, or from public or private research centers.
L'archive ouverte pluridisciplinaire HAL, est destinée au dépôt et à la diffusion de documents scientifiques de niveau recherche, publiés ou non, émanant des établissements d'enseignement et de recherche français ou étrangers, des laboratoires publics ou privés. 


\section{Accepted Manuscript}

Synthesis and biological evaluation of new naphtho- and quinolinocyclopentane derivatives as potent melatoninergic $\left(\mathrm{MT}_{1} / \mathrm{MT}_{2}\right)$ and serotoninergic $\left(5-\mathrm{HT}_{2} \mathrm{C}\right)$ dual ligands

Romain Duroux, Marouan Rami, Elodie Landagaray, Mohamed Ettaoussi, Daniel-

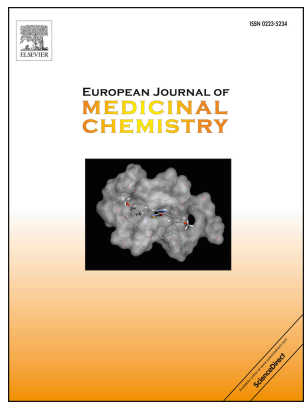
Henri Caignard, Philippe Delagrange, Patricia Melnyk, Saïd Yous

PII: S0223-5234(17)30818-8

DOI: 10.1016/j.ejmech.2017.10.025

Reference: $\quad$ EJMECH 9817

To appear in: European Journal of Medicinal Chemistry

Received Date: 18 September 2017

Revised Date: 8 October 2017

Accepted Date: 9 October 2017

Please cite this article as: R. Duroux, M. Rami, E. Landagaray, M. Ettaoussi, D.-H. Caignard, P. Delagrange, P. Melnyk, Saï. Yous, Synthesis and biological evaluation of new naphtho- and quinolinocyclopentane derivatives as potent melatoninergic $\left(\mathrm{MT}_{1} / \mathrm{MT}_{2}\right)$ and serotoninergic $\left(5-\mathrm{HT}_{2} \mathrm{C}\right)$ dual ligands, European Journal of Medicinal Chemistry (2017), doi: 10.1016/j.ejmech.2017.10.025.

This is a PDF file of an unedited manuscript that has been accepted for publication. As a service to our customers we are providing this early version of the manuscript. The manuscript will undergo copyediting, typesetting, and review of the resulting proof before it is published in its final form. Please note that during the production process errors may be discovered which could affect the content, and all legal disclaimers that apply to the journal pertain. 


\section{GRAPHICAL ABSTRACT}

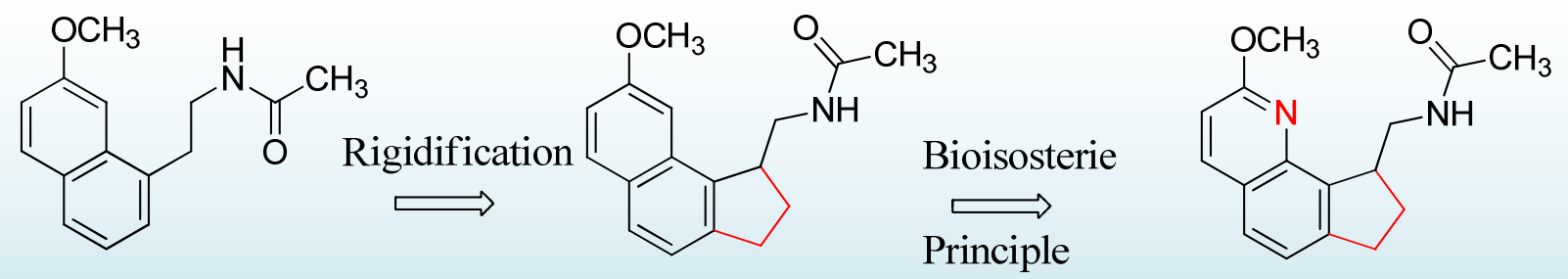

Agomelatine (I)

$\mathrm{Ki}\left(\mathrm{MT}_{1}\right)=0.1 \mathrm{nM}$

$\mathrm{Ki}\left(\mathrm{MT}_{2}\right)=0.2 \mathrm{nM}$

$\mathrm{Ki}\left(5 \mathrm{HT}_{2 \mathrm{c}}\right)=708 \mathrm{nM}$
Naphthocyclopentane (17a)

$\mathrm{Ki}\left(\mathrm{MT}_{1}\right)=0.3 \mathrm{nM}$

$\mathrm{Ki}\left(\mathrm{MT}_{2}\right)=0.2 \mathrm{nM}$

$\mathrm{Ki}\left(5 \mathrm{HT}_{2 \mathrm{c}}\right)=61 \mathrm{nM}$
Quinolinocyclopentane (24a)

$\mathrm{Ki}\left(\mathrm{MT}_{1}\right)=0.4 \mathrm{nM}$

$\mathrm{Ki}\left(\mathrm{MT}_{2}\right)=0.2 \mathrm{nM}$

$\mathrm{Ki}\left(5 \mathrm{HT}_{2 \mathrm{c}}\right)=160 \mathrm{nM}$ 


\section{Synthesis and Biological Evaluation of new Naphtho- and Quinolinocyclopentane Derivatives as Potent Melatoninergic (MT $\left./ \mathbf{M T}_{2}\right)$ and Serotoninergic $\left(5-\mathrm{HT}_{2 \mathrm{C}}\right)$ Dual Ligands}

Romain Duroux, ${ }^{\mathrm{a}}$ Marouan Rami, ${ }^{\mathrm{a}}$ Elodie Landagaray, ${ }^{\mathrm{a}}$ Mohamed Ettaoussi, ${ }^{\mathrm{a},{ }^{*}}$ Daniel-Henri Caignard, ${ }^{\mathrm{b}}$ Philippe Delagrange, ${ }^{\mathrm{b}}$ Patricia Melnyk, ${ }^{\mathrm{a}}$ Saïd Yous ${ }^{\mathrm{a}, *}$

${ }^{a}$ Univ. Lille, Inserm, CHU Lille, UMR-S 1172 - JPArc - Centre de Recherche Jean-Pierre AUBERT Neurosciences et Cancer, F-59000 Lille, France

${ }^{b}$ Unité de Recherche Chimie Neurosciences, Institut de Recherches Servier, 78290 Croissysur-Seine, France.

\section{Corresponding Author :}

"Corresponding author. "Onco and Neurochemistry", Jean-Pierre Aubert Research Center, UMR-S1172, Faculté de Pharmacie (Université Lille). 3, rue du Prof. Laguesse, BP 83, 59006 Lille Cedex, France. Emails: m.ettaoussi@yahoo.fr; said.yous@univ-lille2.fr 


\section{ABSTRACT}

We recently reported a series of naphthofuranic compounds as constrained agomelatine analogues. Herein, in order to explore alternative ethyl amide side chain rigidification, naphthocyclopentane and quinolinocyclopentane derivatives with various acetamide modulations were synthesized and evaluated at both melatonin $\left(\mathrm{MT}_{1}, \mathrm{MT}_{2}\right)$ and serotonin (5$\mathrm{HT}_{2 \mathrm{C}}$ ) receptors. These modifications has led to compounds with promising dual affinity and high MTs receptors agonist activity. Enantiomeric separation was then performed on selected compounds allowing us to identify levogyre enantiomers (-)-17g and (-)-17k as the highest $\left(\mathrm{MT}_{1}, \mathrm{MT}_{2}\right) / 5-\mathrm{HT}_{2 \mathrm{C}}$ dual ligands described nowadays.

Key Words: Melatonin, serotonin, agomelatine, levogyre, dextrogyre 


\section{Introduction}

Since its discovery [1], melatonin remains one of the most studied neurohormones by the scientific community due to its therapeutic perspectives and physio-pathological implications. In fact, during the last half century, melatonin has attracted an extensive campaign of research to fully study its physiological and pathological processes. Overall, however, it is clear that the melatoninergic system still haven't delivered all its secrets! To date, the available evidences indicate that this neurohormone, that is mainly synthesized by the pineal gland following a circadian rhythm [2], is one of the most promising therapeutic targets considering its physiological implications. Interestingly, and consistent with reported findings, melatonin is a key player in several physiological processes such as hormonal secretion, core body temperature regulation and immune system control [3-5] but also participates in several pathological processes including depression and anxiety [6-7]. Although, despite the consented efforts, the melatonin mechanisms of action have not yet been fully resolved. Moreover, it has been demonstrated that, through its signalling pathways, melatonin contributes to the control of replication and survival of many parasites such as Plasmodium falciparum, Plasmodium knowlesi, Trypanosoma cruzi, Toxoplasma gondii, and Leishmania infantum [8-9]. In this context, several in vitro and in vivo studies have shown that melatonin receptor antagonists such as luzindole were able to inhibit the Plasmodium falciparum growth [10-11]. These findings may constitute a new promising approach to research and development of new efficient anti-parasitic agents with rapid action and low toxicity.

The aforementioned physiological and pathological effects of melatonin are attributed to the activation of its binding sites, two major receptors $\left(\mathrm{MT}_{1}\right.$ and $\left.\mathrm{MT}_{2}\right)$ belonging to the superfamily of high-affinity G protein-coupled receptors (GPCRs) [12], and the enzyme quinone reductase 2 (QR2 previousely known as $M T_{3}$ ) [6a]. The design and synthesis of 
melatoninergic ligands has led to a large number of derivatives with different pharmacological profiles. However, only very few melatoninergic ligands (ramelteon, tasimelteon and agomelatine) are commercialized up to now [13-14].

Agomelatine marketed nowadays for the treatment of major depression behaves as a dual ligand acting as a full agonist at melatonin $\mathrm{MT}_{1}$ and $\mathrm{MT}_{2}$ receptor subtypes and an antagonist for serotonin 5- $\mathrm{HT}_{2 \mathrm{C}}$ receptor subtype [15]. The mechanism of action of this new antidepressant is not yet fully elucidated but appears to be caused by the synergy between this combination $\mathrm{MT}_{1} / \mathrm{MT}_{2}$ activation and 5- $\mathrm{HT}_{2 \mathrm{C}}$ deactivation [16]. Research for new successors has led our lab to perform a number of pharmacomodulations of agomelatine. Besides, different positions of the aromatic nucleus, the lateral acetamide chain and the methoxy group were targeted. One of the strategies adopted for the agomelatine analogues was based on the blockade of its major metabolic sites [17-18]. Recently, we also described compounds issued from constrained naphthalenic-like structures especially the (8,9-dihydro-7H-furo[3,2f]chromen-1-yl) derivatives [19] and naphthofuranic ligands [20]. This later modulation has led to compounds with an interesting pharmacological profile and a sub-nanomolar binding affinity especially at melatonin receptors. Insofar, we chose to extent this successful concept into a new conformationally restricted structure. Subsequently, herein we describe the synthesis and pharmacological evaluation of a new series of naphthocyclopentane derivatives as new dual ligands analogues of agomelatine.

Figure 1. Melatonin, Agomelatine and its quinolinic analogue.<smiles>COc1ccc2[nH]cc(CCNC(C)=O)c2c1</smiles>

Melatonin<smiles>COc1ccc2cccc(CCNC(C)=O)c2c1</smiles>

Agomelatine (I)<smiles>COc1ccc2cccc(CCNC(C)=O)c2n1</smiles>

Quinoline 


\section{Results and discussion}

\subsection{Chemistry}

Synthetic routes to the designed compounds are depicted in Schemes 1-5. The synthesis of key intermediate ketones $\mathbf{1 0}$ and $\mathbf{1 1}$ was accomplished as shown in Scheme 1. Compound 10 was prepared from commercially available 2-hydroxy-7-methoxy-naphthalene (1), which was converted to the triflate 2 by action of triflic anhydride. Heck reaction [21] was then realized using ethyl acrylate in the presence of bis(triphenylphosphine)palladium(II) dichloride to give compound (4). Catalytic hydrogenation and subsequent basic hydrolysis gave propionic acid 8. Finally, intramolecular Friedel-Crafts acylation with methanesulfonic acid [22] afforded ketone 10. The same procedure was used starting from commercial 2methoxy-8-bromo-quinoline (3) to get compound 9. Intramolecular Friedel-Crafts acylation on the latter was then realized using chlorosulfonic acid [23] to obtain compound $\mathbf{1 1 .}$<smiles>[R]c1ccc2ccc(OC)cc2c1</smiles>

a

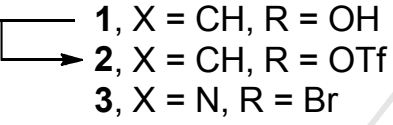<smiles>CCCCC/C=C\c1c(OC)ccc2ccc(/C=C/C(=O)OCC)cc12</smiles>

$4, \mathrm{X}=\mathrm{CH}$

$5, X=N$<smiles></smiles>

$10, \mathrm{X}=\mathrm{CH}$

$11, X=N$<smiles>COc1[X]c2c3c(ccc2cc1)CCC3=O</smiles><smiles>CCOC(=O)CCc1ccc2ccc(OC)[X]c2c1</smiles>

6, $\mathrm{X}=\mathrm{CH}$

$7, X=N$<smiles>COc1ccc2ccc(CCC(=O)O)cc2c1</smiles>
$8, \mathrm{X}=\mathrm{CH}$
$9, X=N$

Scheme $\mathbf{1}^{a}$. Synthesis of key intermediates $\mathbf{1 0}$ and $\mathbf{1 1 .}$

${ }^{a}$ Reagents and conditions: (a) $\mathrm{Tf}_{2} \mathrm{O}, \mathrm{Et}_{3} \mathrm{~N}, \mathrm{CH}_{2} \mathrm{Cl}_{2},-20{ }^{\circ} \mathrm{C}$ to $\mathrm{rt}, 100 \%$; (b) ethyl acrylate, $\mathrm{PdCl}_{2}\left(\mathrm{PPh}_{3}\right)_{2}, \mathrm{Et}_{3} \mathrm{~N}, \mathrm{DMF}, 120{ }^{\circ} \mathrm{C}, 77 \%$ for 4 and $93 \%$ for 5; (c) $\mathrm{Pd} / \mathrm{C}, \mathrm{H}_{2}, \mathrm{CH}_{2} \mathrm{Cl}_{2} / \mathrm{EtOH}, \mathrm{rt}$, 
$96 \%$ for $\mathbf{6}$ and $80 \%$ for 7; (d) (i) $6 \mathrm{M} \mathrm{NaOH}$, EtOH, rt, (ii) $6 \mathrm{M} \mathrm{HCl}, 93 \%$ for $\mathbf{8}$ and $73 \%$ for $\mathbf{9}$; (e) $\mathrm{CH}_{3} \mathrm{SO}_{2} \mathrm{H}, 90^{\circ} \mathrm{C}, 70 \%$; (f) $\mathrm{ClSO}_{3} \mathrm{H}, 0^{\circ} \mathrm{C}$ to rt, $84 \%$.

Naphthocyclopentane derivatives $\mathbf{1 7 - 1 9}$ were synthesized according to the general route outlined in Scheme 2. On one hand, ketone $\mathbf{1 0}$ was first cyanated using trimethylsilyl cyanide [24] followed by a dehydration reaction to afford cyanoindene 12. Alkene was then selectively reduced under $\mathrm{H}_{2}$ atmosphere to give compound 13. The later was $C$-methylated by action of methyl iodide in the presence of sodium hydride afforded compound 14. On the other hand, a Horner-Emmons olefination [25] on ketone 10 with diethyl cyanomethylphosphonate was realized to afford cyanomethylenated compound $\mathbf{1 5}$ which was selectively hydrogenated to afford its saturated analogue (16). Finally, catalytic hydrogenation of cyano derivatives 13, 14 and 16 with Raney-nickel provided aminoalkyl derivatives 17-19. 
<smiles>COc1ccc2ccc3c(c2c1)C(C#N)=CC3</smiles>

12

b $\downarrow$<smiles>COc1ccc2ccc3c(c2c1)C(C#N)CC3</smiles>

13

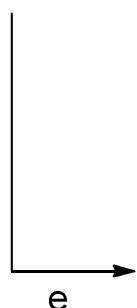

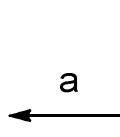<smiles>COc1ccc2ccc3c(c2c1)C(=O)CC3</smiles>

10

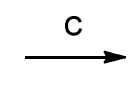<smiles>COc1ccc2ccc3c(c2c1)C(C)(C#N)CC3</smiles>

14

e

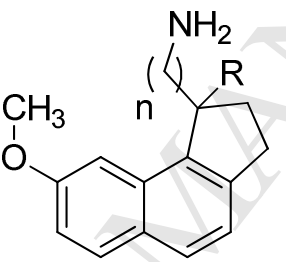

\begin{tabular}{lll}
\hline $\mathrm{N}^{\circ}$ & $\mathrm{n}$ & $\mathrm{R}$ \\
\hline 17 & 1 & $\mathrm{H}$ \\
18 & 2 & $\mathrm{H}$ \\
19 & 1 & $\mathrm{CH}_{3}$ \\
\hline
\end{tabular}

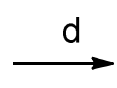<smiles>COc1ccc2ccc3c(c2c1)/C(=C/C#N)CC3</smiles>

15

$\downarrow$<smiles>COc1ccc2ccc3c(c2c1)C(CC#N)CC3</smiles>

16

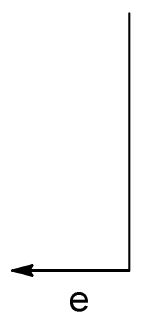

Scheme $2^{\mathrm{a}}$. Synthesis of primary amines 17-19.

${ }^{a}$ Reagents and conditions: a) (i) Trimethylsilyl cyanide, zinc iodide, $\mathrm{CH}_{2} \mathrm{Cl}_{2}$, rt (ii) Acetyl chloride, acetic acid, rt, 83\%; b) $\mathrm{Pd} / \mathrm{C}, \mathrm{H}_{2}, \mathrm{CH}_{2} \mathrm{Cl}_{2} / \mathrm{EtOH}, \mathrm{rt}, 72 \%$; c) $\mathrm{CH}_{3} \mathrm{I}, \mathrm{NaH}, \mathrm{DMF}, 0{ }^{\circ} \mathrm{C}$ to rt, $91 \%$; d) $\mathrm{NaH}$, diethyl cyanomethylphosphonate, THF, $-10{ }^{\circ} \mathrm{C}$ to $\mathrm{rt}, 50 \%$; e) Raney $\mathrm{Ni}$, $\mathrm{H}_{2}$, EtOH, 50 bars, $60^{\circ} \mathrm{C}, 79 \%$ for $\mathbf{1 7}, 93 \%$ for $\mathbf{1 8}$ and $30 \%$ for $\mathbf{1 9 .}$

Preparation of amines $\mathbf{2 4 - 2 5}$ is depicted in scheme 3. To obtain the amine 24, hydrocyanation of ketone $\mathbf{1 1}$ using trimethylsilyl cyanide followed by dehydration to afford cyanoindene 20 was attempted unsuccessfully. Thus, ketone 11 was cyanomethylated by a Horner-Emmons olefination with diethyl cyanomethylphosphonate to give, after (selective) 
hydrogenation, the nitrile $\mathbf{2 1}$. Then, a Curtius reaction was realized where $\mathbf{2 1}$ was first treated under basic condition to afford acid $\mathbf{2 2}$ before being activated to react with sodium azide. The resulting carboxylic azide $\mathbf{2 3}$, not isolated was treated with $\mathrm{NaOH}$ to provide amine $\mathbf{2 4}$ with one-methylene linker. To get amine 25 (two-methylene linker), reduction of cyano function 21 using Raney-nickel as catalyst was realized.

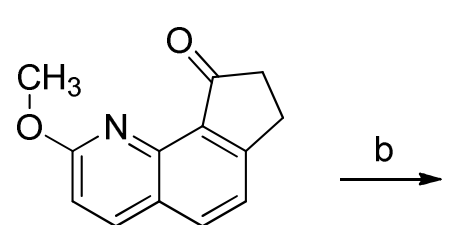

11

$a$<smiles>COc1ccc2ccc3c(c2n1)C(C#N)=CC3</smiles>

20<smiles>COc1ccc2ccc3c(c2n1)C(CC#N)CC3</smiles>

21

c
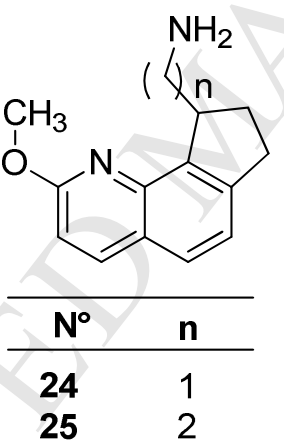

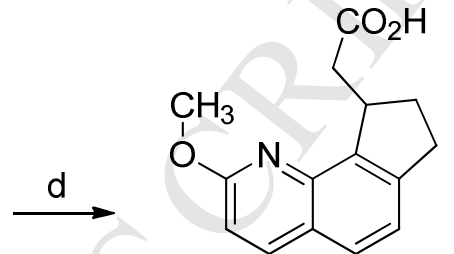

22

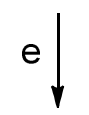<smiles>COc1ccc2ccc3c(c2n1)C(CC(N)=O)CC3</smiles>

23

Scheme $3^{\mathrm{a}}$. Synthesis of amines 24-25.

${ }^{a}$ Reagents and conditions: a) (i) trimethylsilyl cyanide, zinc iodide, $\mathrm{CH}_{2} \mathrm{Cl}_{2}$, rt, (ii) acetyl chloride, acetic acid, rt; b) (i) $\mathrm{NaH}$, diethyl cyanomethylphosphonate, $\mathrm{THF},-10{ }^{\circ} \mathrm{C}$ to $\mathrm{rt}$, (ii) $\mathrm{Pd} / \mathrm{C}, \mathrm{H}_{2}, \mathrm{CH}_{2} \mathrm{Cl}_{2} / \mathrm{EtOH}, \mathrm{rt}, 55 \%$; c) $\mathrm{LiAlH}_{4}, \mathrm{AlCl}_{3}, \mathrm{Et}_{2} \mathrm{O} / \mathrm{CH}_{2} \mathrm{Cl}_{2}, 0{ }^{\circ} \mathrm{C}$ to rt, $90 \%$; d) (i) $6 \mathrm{M}$ $\mathrm{NaOH}$, (ii) $6 \mathrm{M} \mathrm{HCl}$; e) $\mathrm{ClCO}_{2} \mathrm{Et}, \mathrm{Et}_{3} \mathrm{~N}, \mathrm{NaN}_{3}, 0{ }^{\circ} \mathrm{C}$ to rt; f) $1 \mathrm{M} \mathrm{NaOH}, \mathrm{THF}$, rt, $66 \%$ over two steps.

The synthesis of final compounds is illustrated Scheme 4. First, amides ligands (17a19a, 24a-25a, and 17b) were synthesized from corresponding amines (17-19 and 24-25), according to a variant of the Schotten-Baumann procedure, by reaction with the appropriate acid chloride. Carbamate 17c and sulfonamides $17 \mathrm{~d}, 17 \mathrm{e}$ and $19 \mathrm{~b}$ were obtained respectively 
by reaction of amine 17 and 19 with methyl chloroformate or methanesulfonyl chloride. To synthesize primary urea $\mathbf{1 7 f}$ and thiourea $\mathbf{1 7} \mathbf{j}$, reaction between corresponding amine $\mathbf{1 7}$ and potassium cyanate in acidic medium or potassium thiocyanate in dioxane was performed. For the alkylureas (17h-i, 19c-d and 24c) and alkylthioureas (17k-m, 18b and 19e-f) series, treatment of corresponding amines with alkyl isocyanate or alkyl isothiocyanate was realized. Finally, reaction between amines $\mathbf{1 7}$ and $\mathbf{1 9}$ with methyl- $N$-phenylcarbamate in dimethylsulfoxide allowed to get methyl urea (17g and $\mathbf{2 4 b})$ molecules.<smiles>[R20]S(=O)NCC1([R])CCc2ccc3ccc(OC)cc3c21</smiles>

17d-e, 19b<smiles>[R]c1c(OC)ccc2ccc3c(c12)C([R])(ON)CC3</smiles>

$17,18,19,24,25$ a, c, d, e, f<smiles>[X]c1c(OC)ccc2ccc3c(c12)C([R])(NNC([R])[Y])CC3</smiles>

17a-c, 17f-m, 19a, 19c-g, 24a-c, 25a

\begin{tabular}{|c|c|c|c|c|c|c|c|c|}
\hline \multicolumn{2}{|c|}{ Compounds } & $\mathbf{n}$ & $\mathbf{R}_{1}$ & $\mathbf{X}$ & $\mathbf{Y}$ & $\mathbf{R}_{2}$ & Conditions & Rdt \\
\hline \multirow{6}{*}{ Amides } & $17 \mathbf{a}$ & 1 & $\mathrm{H}$ & $\overline{\mathrm{CH}}$ & $\mathrm{O}$ & $\mathrm{CH}_{3}$ & $\mathrm{a}$ & $86 \%$ \\
\hline & $18 \mathrm{a}$ & 2 & $\mathrm{H}$ & $\mathrm{CH}$ & $\mathrm{O}$ & $\mathrm{CH}_{3}$ & $\mathrm{a}$ & $76 \%$ \\
\hline & 19a & 1 & $\mathrm{CH}_{3}$ & $\mathrm{CH}$ & $\mathrm{O}$ & $\mathrm{CH}_{3}$ & $\mathrm{a}$ & $80 \%$ \\
\hline & $24 a$ & 1 & $\mathrm{H}$ & $\mathrm{N}$ & $\mathrm{O}$ & $\mathrm{CH}_{3}$ & $\mathrm{a}$ & $85 \%$ \\
\hline & $25 a$ & 2 & $\mathrm{H}$ & $\mathrm{N}$ & $\mathrm{O}$ & $\mathrm{CH}_{3}$ & $\mathrm{a}$ & $84 \%$ \\
\hline & $17 b$ & 1 & $\mathrm{H}$ & $\mathrm{CH}$ & $\mathrm{O}$ & $\mathrm{CH}_{2} \mathrm{OCH}_{3}$ & $\mathrm{a}$ & $73 \%$ \\
\hline Carbamate & $17 \mathrm{c}$ & 1 & $\mathrm{H}$ & $\mathrm{CH}$ & $\mathrm{O}$ & $\mathrm{OCH}_{3}$ & $\mathrm{a}$ & $88 \%$ \\
\hline \multirow{3}{*}{ Sulfonamides } & $\overline{17 d}$ & 1 & $\mathrm{H}$ & $\mathrm{CH}$ & - & $\mathrm{CH}_{3}$ & $\mathrm{~b}$ & $70 \%$ \\
\hline & $17 \mathrm{e}$ & 1 & $\mathrm{H}$ & $\mathrm{CH}$ & - & $\mathrm{C}_{2} \mathrm{H}_{5}$ & $\mathrm{~b}$ & $70 \%$ \\
\hline & 19b & 1 & $\mathrm{CH}_{3}$ & $\mathrm{CH}$ & - & $\mathrm{CH}_{3}$ & $\mathrm{~b}$ & $50 \%$ \\
\hline \multirow{8}{*}{ Ureas } & $17 f$ & 1 & $\mathrm{H}$ & $\overline{\mathrm{CH}}$ & $\overline{\mathrm{O}}$ & $\mathrm{NH}_{2}$ & $\bar{c}$ & $84 \%$ \\
\hline & $17 \mathrm{~g}$ & 1 & $\mathrm{H}$ & $\mathrm{CH}$ & $\mathrm{O}$ & $\mathrm{NHCH}_{3}$ & $\mathrm{~d}$ & $68 \%$ \\
\hline & $17 \mathrm{~h}$ & 1 & $\mathrm{H}$ & $\mathrm{CH}$ & $\mathrm{O}$ & $\mathrm{NHC}_{2} \mathrm{H}_{5}$ & $\mathrm{e}$ & $57 \%$ \\
\hline & $\mathbf{1 7 i}$ & 1 & $\mathrm{H}$ & $\mathrm{CH}$ & $\mathrm{O}$ & $\mathrm{NHC}_{3} \mathrm{H}_{7}$ & $\mathrm{e}$ & $77 \%$ \\
\hline & $19 c$ & 1 & $\mathrm{CH}_{3}$ & $\mathrm{CH}$ & $\mathrm{O}$ & $\mathrm{NHC}_{2} \mathrm{H}_{5}$ & $\mathrm{e}$ & $67 \%$ \\
\hline & 19d & 1 & $\mathrm{CH}_{3}$ & $\mathrm{CH}$ & $\mathrm{O}$ & $\mathrm{NHC}_{3} \mathrm{H}_{7}$ & $\mathrm{e}$ & $70 \%$ \\
\hline & $24 b$ & 1 & $\mathrm{H}$ & $\mathrm{N}$ & $\mathrm{O}$ & $\mathrm{NHCH}_{3}$ & $\mathrm{~d}$ & $55 \%$ \\
\hline & $24 c$ & 1 & $\mathrm{H}$ & $\mathrm{N}$ & $\mathrm{O}$ & $\mathrm{NHC}_{3} \mathrm{H}_{7}$ & $\mathrm{e}$ & $78 \%$ \\
\hline \multirow{4}{*}{ Thioureas } & $\mathbf{1 7} \mathbf{j}$ & 1 & $\mathrm{H}$ & $\mathrm{CH}$ & $\mathrm{S}$ & $\mathrm{NH}_{2}$ & $\mathrm{f}$ & $25 \%$ \\
\hline & $17 k$ & 1 & $\mathrm{H}$ & $\mathrm{CH}$ & $S$ & $\mathrm{NHCH}_{3}$ & $\mathrm{e}$ & $87 \%$ \\
\hline & 171 & 1 & $\mathrm{H}$ & $\mathrm{CH}$ & $S$ & $\mathrm{NHC}_{2} \mathrm{H}_{5}$ & $\mathrm{e}$ & $64 \%$ \\
\hline & $17 \mathrm{~m}$ & 1 & $\mathrm{H}$ & $\mathrm{CH}$ & $\mathrm{S}$ & $\mathrm{NHC}_{3} \mathrm{H}_{7}$ & $\mathrm{e}$ & $56 \%$ \\
\hline
\end{tabular}




\begin{tabular}{|c|c|ccccccc|}
\hline & $\mathbf{1 9 e}$ & 1 & $\mathrm{CH}_{3}$ & $\mathrm{CH}$ & $\mathrm{S}$ & $\mathrm{NHCH}_{3}$ & $\mathrm{e}$ & $57 \%$ \\
\cline { 2 - 8 } & $\mathbf{1 9 f}$ & 1 & $\mathrm{CH}_{3}$ & $\mathrm{CH}$ & $\mathrm{S}$ & $\mathrm{NHC}_{2} \mathrm{H}_{5}$ & $\mathrm{e}$ & $51 \%$ \\
\cline { 2 - 8 } & $\mathbf{1 9 g}$ & 1 & $\mathrm{CH}_{3}$ & $\mathrm{CH}$ & $\mathrm{S}$ & $\mathrm{NHC}_{3} \mathrm{H}_{7}$ & $\mathrm{e}$ & $41 \%$ \\
\hline
\end{tabular}

Scheme 4. Synthesis of finals compounds 17a-m, 19a-g, 24a-c, 25a.

${ }^{a}$ Reagents and conditions: a) $\mathrm{R}_{2} \mathrm{COCl}, \mathrm{K}_{2} \mathrm{CO}_{3}$, EtOAc/ $\mathrm{H}_{2} \mathrm{O}, 0^{\circ} \mathrm{C}$ to $\mathrm{rt}$; b) $\mathrm{R}_{2} \mathrm{SO}_{2} \mathrm{Cl}, \mathrm{Et}_{3} \mathrm{~N}$, $\mathrm{CH}_{2} \mathrm{Cl}_{2}, 0^{\circ} \mathrm{C}$ to rt; c) $\mathrm{KNCO}, \mathrm{H}_{2} \mathrm{O} / \mathrm{HCl}$, rt; d) $\mathrm{N}$-methylphenylcarbamate, $\mathrm{Et}_{3} \mathrm{~N}$, DMSO $60^{\circ} \mathrm{C}$; e) $\mathrm{R}_{1} \mathrm{NCX}, \mathrm{Et}_{3} \mathrm{~N}, \mathrm{CH}_{2} \mathrm{Cl}_{2}, 0^{\circ} \mathrm{C}$ to rt; f) $\mathrm{KSCN}$, Dioxane, $\mathrm{THF}, 60^{\circ} \mathrm{C}$.

\subsection{Pharmacology}

Biological Results. Synthesized compounds were assayed at human $\mathrm{MT}_{1}$ and $\mathrm{MT}_{2}$ receptors stably transfected in Chinese Hamster Ovarian (CHO) cells, using 2-[ $\left.{ }^{125} \mathrm{I}\right]$ iodomelatonin as radioligand [26]. Serotoninergic 5- $\mathrm{HT}_{2 \mathrm{C}}$ binding affinity was performed using Chinese Hamster Ovarian $(\mathrm{CHO})$ cell lines stably expressing the human 5- $\mathrm{HT}_{2 \mathrm{C}}$ receptors. In Tables 12 are depicted the chemical structures, binding affinities and intrinsic activity of the synthesized ligands.

The actual reported work focuses on the design and synthesis of new constrained naphtho- and and quinolinocyclopentane derivatives as dual ligands for melatonin $\mathrm{MT}_{1} / \mathrm{MT}_{2}$ and serotonin $5-\mathrm{HT}_{2 \mathrm{C}}$ receptor subtypes as successors of agomelatine. This new modulation of the agomelatine structure concerned the inclusion of carbon $\mathrm{C} 2$ of the amide lateral chain into a cyclopentane moiety (Chart 1 ). This free movement restriction of the lateral chain has already been performed as naphthofuranic derivatives and had shown no marked effect at melatonin binding affinity at both $\mathrm{MT}_{1}$ and $\mathrm{MT}_{2}$ in comparison with agomelatine [20]. The same effect was actually observed with synthesized acetamide 17a, however this modulation exhibited a noticeable improvement of the serotoninergic 5- $\mathrm{HT}_{2 \mathrm{C}}$ binding affinity by a factor 10 (Table 1). This pharmacological effect confirms our previous findings. At this point, we 
have no confirmed explanations for such effect and further investigations are in course in order to find out the basis of these results.

\section{Chart 1: Rigidification of Agomelatine}<smiles>COc1ccc2cccc(CCNC(C)=O)c2c1</smiles>

Agomelatine (I) Rigidification ]

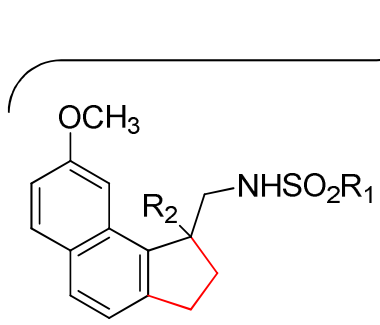

Sulfonamides

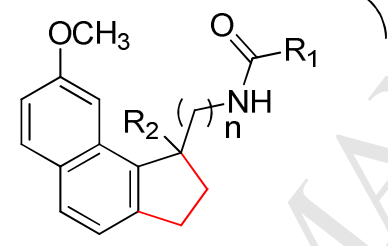

Amides, carbamate, ureas and thioureas
Bioisosterie

$\stackrel{\overrightarrow{\text { Principle }}}{\longrightarrow}$<smiles>COc1ccc2cccc(CCNC(C)=O)c2n1</smiles>

Quinoline $\int$ Rigidification

Bioisosterie Principle<smiles>[R7]C(=O)NCC1([R6])CCc2ccc3ccc(OC)nc3c21</smiles>

Amides, ureas and thioureas

To further investigate the effect of the acetamide function modulation, 17a was considered as a lead compound. Thus, different amides, ureas, thioureas known for their positive effect at both melatonin and serotonin binding affinities were introduced (compounds 17b-17m). The resulted compounds were then tested for their binding affinities at $\mathrm{MT}_{1}, \mathrm{MT}_{2}$ and 5-HT $\mathrm{H}_{2 \mathrm{C}}$. The obtained results are shown in Table 1 and reveal that these modulations had no or a slight effect at both $\mathrm{MT}_{1}$ and $\mathrm{MT}_{2}$ receptor subtypes (compare to 17a) except for thioureas $17 \mathbf{l}$ and $\mathbf{1 7} \mathbf{m}$. Indeed, substitution of the acetamide group of $\mathbf{1 7 a}$ with ethyl $(\mathbf{1 7 l})$ or propyl $(\mathbf{1 7 m})$ thiourea led to a loss of two $\operatorname{logs}$ at the $\mathrm{MT}_{1}$ affinity and one $\log$ at $\mathrm{MT}_{2}$, showing a slight $\mathrm{MT}_{2}$ selectivity. This effect was already reported but we haven't been able to explain the reason yet. In light of the results obtained with acetamide $\mathbf{1 7 a}$, we also extended the length of the ethyl amide lateral chain from two to three carbons (18a). This extension was 
performed to further investigate the role of this lateral chain on the binding affinities especially at 5-HT $2 \mathrm{C}$. However, resulting compound 18a had shown the same profile as $\mathbf{1 7 a}$ with a slight decrease of the binding affinities at both melatonin and serotonin $5-\mathrm{HT}_{2 \mathrm{C}}$ receptor subtypes.

To block one of the metabolic site caused by the oxidation of the lateral amide chain observed with agomelatine derivatives, we introduced an angular methyl group attached to carbon-C1 of the naphthocyclopentane ring (19a-g). Indeed, angular methyl groups are known for their resistance to metabolic oxidation, probably due to local steric hindrance. Interestingly, this modulation led to a same good binding affinities at both $\mathrm{MT}_{1}$ and $\mathrm{MT}_{2}$ and a loss of the serotoninergic $5-\mathrm{HT}_{2 \mathrm{C}}$ binding affinity. Additional investigations are necessary to understand such an effect with this constrained structure. Concerning the introduction of a nitrogen atom through the bioisosteric replacement of naphthalene with quinoline (compound 24a), a similar melatoninergic binding affinity to $\mathbf{1 7 a}$ with a very slight decrease at the at $5-\mathrm{HT}_{2 \mathrm{C}}$ binding affinity is observed. Instead, 25a showed an increase in $\mathrm{MT}_{2}$ binding affinity and a decrease towards $5-\mathrm{HT}_{2 \mathrm{C}}$ compared to its quinolic analogue (18a). Moreover, a pronounced decrease in both $\mathrm{MT} 1$ and $5-\mathrm{HT}_{2 \mathrm{C}}$ receptors is observed comparing 25a and its inferior homologue (24a).

Table 1. $\mathrm{MT}_{1}$ and $\mathrm{MT}_{2}$ binding affinity data of synthesized analogues of melatonin

\begin{tabular}{ccccc}
\hline \multicolumn{2}{c}{ Compound } & \multicolumn{3}{c}{$\mathbf{K}_{\mathbf{i}}(\mathbf{n M})[I 95](n)$} \\
\cline { 2 - 4 } & $\mathbf{A g}(\mathbf{I})$ & $0.1[0.1 ; 0.1](2)$ & $0.2[0.1 ; 0.6](2)$ & $708[46 ; 895](2)$ \\
\cline { 2 - 4 } & $\mathbf{1 7 a}$ & $0.3[0.2 ; 1.3](2)$ & $0.2[0.02 ; 0.6](2)$ & $61[35 ; 129](2)$ \\
\multirow{4}{*}{ Amides } & $\mathbf{1 8 a}$ & $4[3.0 ; 5.2](2)$ & $2[0.9 ; 2.1](2)$ & $180[102 ; 335](2)$ \\
& $\mathbf{1 9 a}$ & $0.1[0.07 ; 0.7](2)$ & $0.1[0.05 ; 0.7](2)$ & $>10000$ \\
& $\mathbf{1 7 b}$ & $0.6[0.4 ; 1.1](2)$ & $0.1[0.07 ; 0.3](2)$ & $200[123 ; 302](2)$ \\
& $\mathbf{2 4 a}$ & $0.4[0.2 ; 0.8](2)$ & $0.2[0.1 ; 0.4](2)$ & $160[125 ; 212](2)$
\end{tabular}




\begin{tabular}{|c|c|c|c|c|}
\hline & $25 \mathbf{a}$ & $5[4.3 ; 6.2](2)$ & $0.8[0.65 ; 1.1](2)$ & 1600 \\
\hline Carbamate & $17 \mathrm{c}$ & $2[0.9 ; 2.3](2)$ & $0.4[0.1 ; 0.7](2)$ & $100[83 ; 133](2)$ \\
\hline \multirow{3}{*}{$\begin{array}{l}\text { Sulfon- } \\
\text { amides }\end{array}$} & 17d & $0.8[0.2 ; 1.3](2)$ & $0.1[0.07 ; 0.4](2)$ & $580[437 ; 723](2)$ \\
\hline & $19 b$ & $0.6[0.3 ; 1.1](2)$ & $0.2[0.09 ; 0.4](2)$ & $>10000$ \\
\hline & $17 \mathrm{e}$ & $7[4.3 ; 9.2](2)$ & $0.4[0.1 ; 0.6](2)$ & $400[277 ; 578](2)$ \\
\hline \multirow{10}{*}{ Ureas } & $17 f$ & $0.3[0.1 ; 0.5](2)$ & $0.1[0.08 ; 0.4](2)$ & $145[97 ; 223](2)$ \\
\hline & $17 \mathrm{~g}$ & $0.6[0.5 ; 0.8](2)$ & $0.2[0.07 ; 0.5](2)$ & $170[135 ; 217](2)$ \\
\hline & $(+)-17 g$ & $32[28 ; 41](2)$ & $970[734 ; 1120](2)$ & $>10000$ \\
\hline & $(-)-17 g$ & $0.4[0.1 ; 0.9](2)$ & $0.07[0.02 ; 0.1](2)$ & $15[7 ; 26](2)$ \\
\hline & $17 \mathrm{~h}$ & $2[1 ; 2.7](2)$ & $0.1[0.07 ; 0.3](2)$ & $60[53 ; 69](2)$ \\
\hline & $17 \mathbf{i}$ & $5[3.5 ; 6.2](2)$ & $0.2[0.1 ; 0.5](2)$ & $190[123 ; 218](2)$ \\
\hline & $19 c$ & $0.8[0.6 ; 1.3](2)$ & $0.3[0.1 ; 0.5](2)$ & $>10000$ \\
\hline & 19d & $2[1.1 ; 3.7](2)$ & $0.2[0.09 ; 0.4](2)$ & $>10000$ \\
\hline & $24 b$ & $1[0.7 ; 1.6](2)$ & $0.2[0.11 ; 0.3](2)$ & $340[297 ; 394](2)$ \\
\hline & $24 c$ & $7[5.2 ; 9.3](2)$ & $0.4[0.2 ; 0.7](2)$ & $285[207 ; 410](2)$ \\
\hline \multirow{9}{*}{ Thioureas } & $\mathbf{1 7} \mathbf{j}$ & $6[4.7 ; 8.3](2)$ & $0.4[0.1 ; 0.9](2)$ & $72[43 ; 117](2)$ \\
\hline & $17 \mathbf{k}$ & $4[2.7 ; 7.1](2)$ & $0.3[0.1 ; 0.7](2)$ & $30[18 ; 54](2)$ \\
\hline & $(+)-17 k$ & $99[43 ; 127](2)$ & $9[2 ; 14](2)$ & $>10000$ \\
\hline & $(-)-17 k$ & $3[1.6 ; 4.2](2)$ & $0.1[0.08 ; 0.17](2)$ & $9[3 ; 11](2)$ \\
\hline & 171 & $29[15 ; 47](2)$ & $2[1.1 ; 3.1](2)$ & $8[3 ; 16](2)$ \\
\hline & $17 \mathrm{~m}$ & $63[48 ; 79](2)$ & $3[1.6 ; 5.1](2)$ & $42[23 ; 75](2)$ \\
\hline & $19 e$ & $1[0.3 ; 2.5](2)$ & $0.2[0.1 ; 0.4](2)$ & $>10000$ \\
\hline & 19f & $4[2.1 ; 6.2](2)$ & $3[1.3 ; 5.7](2)$ & $>10000$ \\
\hline & $19 \mathrm{~g}$ & $9[6.2 ; 13](2)$ & $0.3[0.1 ; 0.7](2)$ & $>10000$ \\
\hline
\end{tabular}

Finally, replacement of the amide function of $17 \mathbf{a}$ by a methylurea (17g) and a methylthiourea (17k) led to the most interesting compounds profiles that we are looking for with a good balance between the melatoninergic and serotoninergic binding affinities. Compounds $17 \mathrm{~g}$ and $\mathbf{1 7} \mathbf{k}$ were then submitted to enantiomeric resolution leading to two pairs of compounds: (+)-17g, (-)-17g, (+)-17k and (-)-17k. Evaluation of these four compounds revealed that binding to melatoninergic $\mathrm{MT}_{1}, \mathrm{MT}_{2}$ and serotoninergic $5-\mathrm{HT}_{2 \mathrm{C}}$ receptors is 
enantioselective. Indeed, levogyre enantiomers (-)-17g and (-)-17k were more potent than their dextrogyre counterpart and their mixtures (Table 1). These two compounds represent the most interesting dual ligands for described nowadays. However, further investigations are needed in order to determine the enantioselectivity effect on the ADME properties. Intrinsic activity evaluation for all compounds towards melatonin $\mathrm{MT}_{1}$ and $\mathrm{MT}_{2}$ receptors was performed and the results are depicted in Table 2. In general, two intrinsic activity profiles were observed. A first group with $\mathrm{MT}_{1} / \mathrm{MT}_{2}$ partial agonist/full agonist profile including compounds 17a, 17b, 17h, 17g, 17i, 17k, 19c, 19d and (-)-17g. A second group with an $\mathrm{MT}_{1} / \mathrm{MT}_{2}$ partial agonist profile was reported and includes compounds $\mathbf{1 7 c}, \mathbf{1 7 d}, \mathbf{1 7 f}, \mathbf{1 7} \mathbf{j}, \mathbf{1 7 l}$, 17m, 19a, 19e, 19f, 19g, 24b and 24c. Evaluation of intrinsic activity of these compounds at 5- $\mathrm{HT}_{2 \mathrm{C}}$ showed an antagonist activity profile (data not shown).

Table 2. Intrinsic activity of most interesting synthesized compounds.

\begin{tabular}{ccc|cc}
\hline Cpd. & \multicolumn{2}{c|}{$h-M T_{1}$} & \multicolumn{2}{c}{$h-M T_{2}$} \\
\hline & $\mathbf{E C}_{\mathbf{5 0}}(\mathbf{n M})[195](n)$ & $\mathbf{E}_{\mathbf{m a x}}(\boldsymbol{\%}) \pm E S M(n)$ & $\mathbf{E C}_{\mathbf{5 0}}(\mathbf{n M})[I 95](n)$ & $\mathbf{E}_{\mathbf{m a x}}(\boldsymbol{\%}) \pm E S M(n)$ \\
\hline $\mathbf{I}$ & $1.4[0.7 ; 2.5](4)$ & $99 \pm 6(4)$ & $0.18[0.1 ; 0.39](3)$ & $91 \pm 7(3)$ \\
$\mathbf{1 7 a}$ & $0.9[0.9 ; 2.4](2)$ & $78 \pm 1(2)$ & $0.2[0.1 ; 0.5](2)$ & $118 \pm 37(2)$ \\
$\mathbf{1 9 a}$ & $0.2[0.1 ; 0.4](2)$ & $79 \pm 3(2)$ & $0.2[0.09 ; 0.42](2)$ & $87 \pm 3(2)$ \\
$\mathbf{1 7 b}$ & $5[3.1 ; 6.4](2)$ & $81 \pm 3(2)$ & $0.4[0.1 ; 0.8](2)$ & $99 \pm 2(2)$ \\
$\mathbf{2 4 a}$ & $0.05[0.02 ; 0.08](2)$ & $53 \pm 4(2)$ & - & - \\
$\mathbf{1 7 d}$ & $4[2.2 ; 6.8](2)$ & $30 \pm 1(2)$ & $1[0.4 ; 2.8](2)$ & $63 \pm 2(2)$ \\
$\mathbf{1 7 e}$ & 10000 & - & 1000 & - \\
$\mathbf{1 7 c}$ & - & - & $5[2.3 ; 7.9](2)$ & $71 \pm 2(2)$ \\
$\mathbf{1 7 f}$ & $2[0.7 ; 4.1](2)$ & $53 \pm 3(2)$ & $0.9[0.5 ; 1.8](2)$ & $56 \pm 1(2)$ \\
$\mathbf{1 7 g}$ & $5[2.9 ; 8.4](2)$ & $66 \pm 4(2)$ & $3[1.7 ; 5.4](2)$ & $95 \pm 5(2)$ \\
$\mathbf{( - ) - 1 7 g}$ & $3[1.7 ; 4.4](2)$ & $51 \pm 5(2)$ & $0.6[0.4 ; 0.7](2)$ & $133 \pm 21(2)$ \\
$\mathbf{1 7 h}$ & $20[14 ; 27](2)$ & $64 \pm 2(2)$ & $3[1.7 ; 4.3](2)$ & $103 \pm 2(2)$ \\
$\mathbf{1 9 c}$ & $5[2.3 ; 9.1](2)$ & $66 \pm 3(2)$ & $0.3[0.1 ; 0.6](2)$ & $109 \pm 4(2)$ \\
$\mathbf{1 7 i}$ & $30[13 ; 68](2)$ & $76 \pm 6(2)$ & $20[10 ; 50](2)$ & $96 \pm 10(2)$ \\
& & &
\end{tabular}




\begin{tabular}{ccc|cc}
$\mathbf{1 9 d}$ & $9[5.3 ; 11.7](2)$ & $74 \pm 1(2)$ & $0.7[0.4 ; 1.1](2)$ & $116 \pm 2(2)$ \\
$\mathbf{2 4 b}$ & $0.2[0.08 ; 0.5](2)$ & $42 \pm 4(2)$ & - & - \\
$\mathbf{2 4 c}$ & $0.9[0.7 ; 1.4](2)$ & $35 \pm 1(2)$ & - & $39 \pm 3(2)$ \\
$\mathbf{1 7 j}$ & $16[0.9 ; 2.4](2)$ & $32 \pm 3(2)$ & $5[2.9 ; 6.2](2)$ & $98 \pm 2(2)$ \\
$\mathbf{1 7 k}$ & $8[6.3 ; 10.5](2)$ & $52 \pm 4(2)$ & $6[4.3 ; 8.8](2)$ & - \\
$\mathbf{( - ) - 1 7 k}$ & $10[7.2 ; 13.7](2)$ & $63 \pm 2(2)$ & - & $84 \pm 5(2)$ \\
$\mathbf{1 9 e}$ & $6[3.4 ; 9.2](2)$ & $44 \pm 1(2)$ & $3[1.4 ; 5.2](2)$ & $67 \pm 2(2)$ \\
$\mathbf{1 7 l}$ & $70[63 ; 79](2)$ & $38 \pm 6(2)$ & $50[37 ; 67](2)$ & $64 \pm 1(2)$ \\
$\mathbf{1 9 f}$ & $10[7.1 ; 14.3](2)$ & $47 \pm 2(2)$ & $2[1.3 ; 3.1](2)$ & $\mathrm{ND}$ \\
$\mathbf{1 7 m}$ & $20[15 ; 36](3)$ & $40 \pm 12(3)$ & $>10000$ & $83 \pm 3(2)$ \\
$\mathbf{1 9 g}$ & $100[83 ; 119](2)$ & $50 \pm 1(2)$ & $4[2.6 ; 6.3](2)$ & \\
\hline
\end{tabular}

$\mathrm{EC}_{50}$ values are geometric mean values (with $95 \%$ confidence limits in parentheses) Emax values are arithmetic mean \pm S.E.M. ND: Not determined

\section{Conclusions}

The present work deals with the optimization of a new series of constrained agomelatine analogues. Indeed, constrained structures revealed to be of interest in our case and the inclusion of the ethyl amide side chain into a naphthocyclopentane structure seems to confirm our actual strategy. Obtained acetamide 17a exhibited a very interesting pharmacological profile in comparison to agomelatine. Modulation of the acetamide group of $\mathbf{1 7 a}$ revealed once again that the nature of this group is important to the melatonin binding affinity but critical to the serotonin $5-\mathrm{HT}_{2 \mathrm{C}}$ receptor. Among prepared derivatives, methyl urea $\mathbf{1 7 g}$ and methyl thiourea $\mathbf{1 7} \mathbf{k}$ exhibited the most interesting profiles and showed the enantioselective character of the binding affinity at these three receptors. Thus, this enantiomeric separation allows us to describe the levogyre enantiomers (-)-17g and (-)-17k as the highest $\left(\mathrm{MT}_{1}\right.$, $\left.\mathrm{MT}_{2}\right) / 5 \mathrm{HT}_{2 \mathrm{C}}$ dual ligands found nowadays. 


\section{Experimental section}

\subsection{Chemistry}

Chemicals and solvents were obtained from commercial sources, and used without further purification unless otherwise noted. Reactions were monitored by TLC performed on Macherey-Nagel Alugram ${ }^{\circledR}$ Sil 60/UV 254 sheets (thickness $0.2 \mathrm{~mm}$ ). Purification of products was carried out by recrystallization or column chromatography. Column chromatography was carried out using Macherey-Nagel silica gel (230-400 mesh). Melting points were determined on a Büchi SMP-20 capillary apparatus and are uncorrected. FT-IR spectra were recorded on a Thermo Nicolet Avatar 320 FT-IR spectrometer. NMR spectra were recorded on a Bruker DRX 300 spectrometer (operating at $300 \mathrm{MHz}$ for ${ }^{1} \mathrm{H}$ and $75 \mathrm{MHz}$ for ${ }^{13} \mathrm{C}$ ). Chemical shifts are expressed in ppm relative to either tetramethylsilane (TMS). Chemical shifts are reported as position $(\delta$ in ppm), multiplicity $(\mathrm{s}=$ singlet, $\mathrm{d}=$ doublet, $\mathrm{t}=$ triplet, $\mathrm{q}=$ quartet, $\mathrm{p}=$ pentet, $\mathrm{dd}=$ double doublet, $\mathrm{br}=$ broad and $\mathrm{m}=$ multiplet $)$, coupling constant $(J$ in Hz$)$, relative integral and assignment. Mass spectra were recorded on a Varian triple quadrupole 1200W mass spectrometer equipped with a non-polar C18 TSK-gel Super ODS $(4.6 \times 50 \mathrm{~mm})$ column, using electrospray ionization and a UV detector (diode array). HRMS-ESI spectra were recorded on a Thermo Scientific Exactive spectrometer.

\section{2. (7-Methoxy-2-naphthyl)trifluoromethanesulfonate (2).}

A solution of trifluoromethane sulfonic anhydride $(19.92 \mathrm{~mL}, 120 \mathrm{mmol})$ in methylene chloride $(20 \mathrm{~mL})$ was added dropwise to a stirred solution of 7-methoxy-2-naphthol 1 (17.42 $\mathrm{g}, 100 \mathrm{mmol})$ and triethylamine $(20.85 \mathrm{~mL}, 150 \mathrm{mmol})$ in methylene chloride $(320 \mathrm{~mL})$ at -70 ${ }^{\circ} \mathrm{C}$. The reaction mixture was stirred for $20 \mathrm{~min}$ at room temperature, hydrolyzed with water and extracted with methylene chloride. The combined organic layers were washed with water, brine, dried over $\mathrm{MgSO}_{4}$, filtered and concentrated under vacuum. The product was obtained quantitatively without further purification as a yellow oil; ${ }^{1} \mathrm{H} \mathrm{NMR}\left(300 \mathrm{MHz}, \mathrm{CDCl}_{3}\right) \delta: 7.84$ 
(d, 1H, $9.0 \mathrm{~Hz}), 7.78(\mathrm{~d}, 1 \mathrm{H}, 9.0 \mathrm{~Hz}), 7.65(\mathrm{~d}, 1 \mathrm{H}, 2.4 \mathrm{~Hz}), 7.25-7.21(\mathrm{~m}, 2 \mathrm{H}), 7.15(\mathrm{~d}, 1 \mathrm{H}, 2.7$ Hz), 3.94 (s, 3H); LC-MS: m/z=275 $\left(\mathrm{MH}^{+}\right)$.

\subsection{Ethyl (E)-3-(7-methoxynaphtalen-2-yl)prop-2-enoate (4).}

To a solution of 2 (30.63 g, $100 \mathrm{mmol})$ in DMF (150 mL) under an inert atmosphere, were added ethyl acrylate $(11.97 \mathrm{~mL}, 110 \mathrm{mmol})$, bis(triphenylphosphine) palladium chloride $(7.72 \mathrm{~g}, 11 \mathrm{mmol})$ and triethylamine $(15.29 \mathrm{~mL}, 110 \mathrm{mmol})$. The reaction mixture was refluxed at $120{ }^{\circ} \mathrm{C}$ for $15 \mathrm{~h}$, cooled to room temperature, hydrolyzed with water and then extracted twice with ethyl acetate. The combined organic layers were washed with a $1 \mathrm{M}$ solution of $\mathrm{HCl}$, water and brine, dried over $\mathrm{MgSO}_{4}$, filtered and evaporated under reduced pressure. The residue was purified by column chromatography $\left(\mathrm{SiO}_{2}\right.$, cyclohexane/ EtOAc: 7/3) to give $4(77 \%)$ as a white solid; mp $90-92{ }^{\circ} \mathrm{C} ;{ }^{1} \mathrm{H}$ NMR $\left(300 \mathrm{MHz}, \mathrm{CDCl}_{3}\right) \delta: 7.87-7.72$ (m, 2H), $7.77(\mathrm{~d}, 1 \mathrm{H}, 8.4 \mathrm{~Hz}), 7.74(\mathrm{~d}, 1 \mathrm{H}, 8.7 \mathrm{~Hz}), 7.54(\mathrm{dd}, 1 \mathrm{H}, 8.4 \mathrm{~Hz}$ and $1.5 \mathrm{~Hz}), 7.19$ (dd, 1H, 8.7 Hz and 2.4 Hz), $7.16(\mathrm{~d}, 1 \mathrm{H}, 2.4 \mathrm{~Hz}), 6.55(\mathrm{~d}, 1 \mathrm{H}, 15.9 \mathrm{~Hz}), 4.30(\mathrm{q}, 2 \mathrm{H}, 7.2 \mathrm{~Hz})$, $3.95(\mathrm{~s}, 3 \mathrm{H}), 1.37(\mathrm{t}, 3 \mathrm{H}, 7.2 \mathrm{~Hz})$; IR $\left(v, \mathrm{~cm}^{-1}\right): 1705(\mathrm{CO})$; LC-MS: $\mathrm{m} / z=257\left(\mathrm{MH}^{+}\right)$.

\subsection{Ethyl 3-(7-methoxynaphtalen-2-yl)propanoate (6).}

A solution of $4(10 \mathrm{~g}, 40 \mathrm{mmol})$ in $60 \mathrm{~mL}$ of ethanol/ methylene chloride (1/1) with palladium $10 \%$ on charcoal was stirred under hydrogen atmosphere at room temperature for 6h. The mixture was then filtered and concentrated under reduced pressure. The crude product was recrystallized from petroleum ether to give $6(96 \%)$ as a white solid; mp $82-84{ }^{\circ} \mathrm{C} ;{ }^{1} \mathrm{H}$ NMR (300 MHz, $\left.\mathrm{CDCl}_{3}\right) \delta: 7.72-7.69(\mathrm{~m}, 2 \mathrm{H}), 7.56(\mathrm{~s}, 1 \mathrm{H}), 7.21(\mathrm{dd}, 1 \mathrm{H}, 8.4 \mathrm{~Hz}$ and 1.5 Hz), 7.12-7.09 (m, 2H), 4.15 (q, 2H, $6.9 \mathrm{~Hz}), 3.93$ (s, 3H), 3.10 (t, 2H, $7.5 \mathrm{~Hz}), 2.71$ (t, 2H, $7.5 \mathrm{~Hz}), 1.24(\mathrm{t}, 3 \mathrm{H}, 6.9 \mathrm{~Hz})$; IR $\left(v, \mathrm{~cm}^{-1}\right): 1720(\mathrm{CO})$; LC-MS: $m / z=259\left(\mathrm{MH}^{+}\right)$.

\subsection{3-(7-Methoxynaphtalen-2-yl)propionic acid (8).}

Compound 6 (9 g, $34.85 \mathrm{mmol})$ was dissolved in ethanol $(40 \mathrm{~mL})$, followed by the addition of $6 \mathrm{M}$ solution of $\mathrm{NaOH}(40 \mathrm{~mL})$. The reaction mixture was stirred at room 
temperature, for $3 \mathrm{~h}$, hydrolyzed with a $2 \mathrm{M}$ solution of $\mathrm{HCl}$ and extracted twice with methylene chloride. The combined organic layers were washed with water, dried over $\mathrm{MgSO}_{4}$, filtered and concentrated under reduced pressure. The crude product was recrystallized from methanol to afford $8(93 \%)$ as a white solid; mp $175-177{ }^{\circ} \mathrm{C} ;{ }^{1} \mathrm{H}$ NMR $\left(300 \mathrm{MHz}, \mathrm{CDCl}_{3}\right) \delta: 10.2$ (br s, 1H), 7.73-7.70 (m, 2H), $7.57(\mathrm{~s}, 1 \mathrm{H}), 7.21(\mathrm{dd}, 1 \mathrm{H}, 8.4 \mathrm{~Hz}$ and 1.8 Hz), 7.13-7.10 (m, 2H), $3.93(\mathrm{~s}, 3 \mathrm{H}), 3.12(\mathrm{t}, 2 \mathrm{H}, 7.5 \mathrm{~Hz}), 2.79(\mathrm{t}, 2 \mathrm{H}, 7.5 \mathrm{~Hz})$; IR (v, $\left.\mathrm{cm}^{-1}\right): 2833(\mathrm{OH}), 1694(\mathrm{CO}) ; \mathrm{LC}-\mathrm{MS}: \mathrm{m} / z=231\left(\mathrm{MH}^{+}\right)$.

4.6. 8-Methoxy-2,3-dihydro-1H-cyclopenta[a]naphthalen-1-one (10).

Methanesulfonic acid (20 mL) was added dropwise to the acid 8 (6.20 g, $26.90 \mathrm{mmol})$. Stirring was maintained for $2 \mathrm{~h}$ at $90{ }^{\circ} \mathrm{C}$, and then the mixture was poured into water and extracted twice with diethyl ether. The combined organic phases were washed with water, dried over $\mathrm{MgSO}_{4}$, filtered and concentrated under reduced pressure. The residue was recrystallized from acetonitrile to afford $\mathbf{1 0}(70 \%)$ as a white solid; mp 122-124 ${ }^{\circ} \mathrm{C} ;{ }^{1} \mathrm{H}$ NMR $\left(300 \mathrm{MHz}, \mathrm{CDCl}_{3}\right) \delta: 8.60(\mathrm{~d}, 1 \mathrm{H}, 2.4 \mathrm{~Hz}), 7.97(\mathrm{~d}, 1 \mathrm{H}, 8.4 \mathrm{~Hz}), 7.79$ (d, 1H, $\left.9.0 \mathrm{~Hz}\right), 7.38$ (d, 1H, $8.4 \mathrm{~Hz}), 7.20(\mathrm{dd}, 1 \mathrm{H}, 9.0 \mathrm{~Hz}$ and $2.4 \mathrm{~Hz}), 4.00(\mathrm{~s}, 3 \mathrm{H}), 3.23-3.20(\mathrm{~m}, 2 \mathrm{H}), 2.83-2.79$ (m, $2 \mathrm{H}) ; \mathrm{IR}\left(\mathrm{v}, \mathrm{cm}^{-1}\right): 1681(\mathrm{CO}) ; \mathrm{LC}-\mathrm{MS}: \mathrm{m} / \mathrm{z}=213\left(\mathrm{MH}^{+}\right)$.

4.7. (8-Methoxy-3H-cyclopenta[a]naphthalen-1-yl)carbonitrile (12).

Step 1: To a solution of $\mathbf{1 0}(4.74 \mathrm{~g}, 22.33 \mathrm{mmol})$ in DCM $(70 \mathrm{~mL})$, was added zinc iodide (142 mg, $0.45 \mathrm{mmol})$ trimethylsilyl cyanide was then added dropwise at $0{ }^{\circ} \mathrm{C}(7 \mathrm{~mL}$, $55.83 \mathrm{mmol}$ ). The mixture was stirred at room temperature during $3 \mathrm{~h}$ and a saturated solution of $\mathrm{NaHCO}_{3}$ was added. Extraction was realized with methylene chloride and the organic layer was washed with water, dried over $\mathrm{MgSO}_{4}$, filtered and concentrated under vacuum. The residue was purified by column chromatography $\left(\mathrm{SiO}_{2}\right.$, cyclohexane/EtOAc: $\left.9 / 1\right)$ and recrystallized from cyclohexane to afford 8-Methoxy-1-(((trimethylsilyl)oxy)-2,3-dihydro$1 H$-cyclopenta $[a]$ naphthalen-1-yl) carbonitrile $(83 \%)$ as a yellow solid; mp $67-69{ }^{\circ} \mathrm{C} ;{ }^{1} \mathrm{H}$ 
NMR (300 MHz, $\left.\mathrm{CDCl}_{3}\right) \delta: 7.80-7.78(\mathrm{~m}, 2 \mathrm{H}), 7.68(\mathrm{~d}, 1 \mathrm{H}, 2.7 \mathrm{~Hz}), 7.22(\mathrm{~d}, 1 \mathrm{H}, 8.4 \mathrm{~Hz}), 7.16$ (dd, 1H, $9.0 \mathrm{~Hz}$ and $2.7 \mathrm{~Hz}), 3.98(\mathrm{~s}, 3 \mathrm{H}), 3.30-2.99(\mathrm{~m}, 3 \mathrm{H}), 2.58(\mathrm{~m}, 1 \mathrm{H}), 0.29(\mathrm{~s}, 9 \mathrm{H})$; IR (v, $\left.\mathrm{cm}^{-1}\right): 2230(\mathrm{CN}) ;$ LC-MS: $m / z=312\left(\mathrm{MH}^{+}\right)$.

Step 2: To a solution of this compound (3 $\mathrm{g}, 9.63 \mathrm{mmol})$ in acetic acid (3 $\mathrm{mL})$ was added dropwise at $0{ }^{\circ} \mathrm{C}$ acetyl chloride $(2.05 \mathrm{~mL}, 28.9 \mathrm{mmol})$. The mixture was stirred at room temperature during $1 \mathrm{~h}$, hydrolyzed and extracted with methylene chloride. The organic layer was washed with water, dried over $\mathrm{MgSO}_{4}$, filtered and concentrated under vacuum. The residue was recrystallized from toluene to afford $\mathbf{1 2}(83 \%)$ as a white solid; mp $111-112{ }^{\circ} \mathrm{C}$; ${ }^{1} \mathrm{H}$ NMR (300 MHz, $\left.\mathrm{CDCl}_{3}\right) \delta: 8.22(\mathrm{~d}, 1 \mathrm{H}, 2.4 \mathrm{~Hz}), 7.83$ (d, 1H, 9.0 Hz), $7.76(\mathrm{~d}, 1 \mathrm{H}, 8.1$ Hz), 7.51-7.48 (m, 2H), 7.20 (dd, 1H, 9.0 Hz and 2.4 Hz), $4.01(\mathrm{~s}, 3 \mathrm{H}), 3.75$ (d, 2H, $1.5 \mathrm{~Hz})$; IR $\left(v, \mathrm{~cm}^{-1}\right): 2229(\mathrm{CN}) ; \mathrm{LC}-\mathrm{MS}: \mathrm{m} / z=222\left(\mathrm{MH}^{+}\right)$.

4.8. (8-Methoxy-2,3-dihydro-1H-cyclopenta[a]naphthalen-1-yl)carbonitrile (13).

A solution of $12(1.10 \mathrm{~g}, 5 \mathrm{mmol})$ in $60 \mathrm{~mL}$ of ethanol/dichloromethane (1/2) with palladium $10 \%$ on charcoal was stirred under hydrogen atmosphere at room temperature for 6 h. The mixture was filtered, concentrated under reduced pressure. The crude product was recrystallized from toluene to give $\mathbf{1 3}(72 \%)$ as a white solid; mp 103-105 ${ }^{\circ} \mathrm{C} ;{ }^{1} \mathrm{H}$ NMR (300 $\left.\mathrm{MHz}, \mathrm{CDCl}_{3}\right) \delta: 7.80(\mathrm{~d}, 1 \mathrm{H}, 9.0 \mathrm{~Hz}), 7.75(\mathrm{~d}, 1 \mathrm{H}, 8.1 \mathrm{~Hz}), 7.28(\mathrm{~d}, 1 \mathrm{H}, 8.1 \mathrm{~Hz}), 7.21(\mathrm{~d}, 1 \mathrm{H}$, $2.4 \mathrm{~Hz}), 7.17(\mathrm{dd}, 1 \mathrm{H}, 9.0 \mathrm{~Hz}$ and $2.4 \mathrm{~Hz}), 4.47(\mathrm{dd}, 1 \mathrm{H}, 8.4 \mathrm{~Hz}$ and $5.4 \mathrm{~Hz}), 3.98(\mathrm{~s}, 3 \mathrm{H})$, 3,36 (m, 1H), $3.16(\mathrm{~m}, 1 \mathrm{H}), 2.77-2.70(\mathrm{~m}, 2 \mathrm{H})$; IR (v, $\left.\mathrm{cm}^{-1}\right): 2227(\mathrm{CN})$; LC-MS: $\mathrm{m} / \mathrm{z}=224$ $\left(\mathrm{MH}^{+}\right)$.

4.9. (8-Methoxy-1-methyl-2,3-dihydro-1H-cyclopenta[a]naphtalen-1-yl)carbonitrile (14).

To a solution of 13 (0.86 g, $3.85 \mathrm{mmol})$ in DMF (30 mL) under argon atmosphere was added at $0{ }^{\circ} \mathrm{C}$ sodium hydride $(185 \mathrm{mg}, 7.7 \mathrm{mmol})$. The mixture was stirred at $0{ }^{\circ} \mathrm{C}$ during 15 min, then methyl iodide $(820 \mathrm{mg}, 5.78 \mathrm{mmol})$ was added and stirring was continued for additional $45 \mathrm{~min}$. The mixture was hydrolyzed with water and extracted with ethyl acetate. 
The organic layer was washed with water, dried over $\mathrm{MgSO}_{4}$, filtered and concentrated under reduced pressure. The residue was purified by flash chromatography $\left(\mathrm{SiO}_{2}\right.$, cyclohexane/EtOAc: 5/5) and recrystallized from cyclohexane to afford $\mathbf{1 4}(91 \%)$ as a white solid; mp 95-97 ${ }^{\circ} \mathrm{C} ;{ }^{1} \mathrm{H}$ NMR $\left(300 \mathrm{MHz}, \mathrm{CDCl}_{3}\right) \delta: 7.79$ (d, 1H, $\left.9.0 \mathrm{~Hz}\right), 7.74(\mathrm{~d}, 1 \mathrm{H}, 8.1$ Hz), 7.54 (d, 1H, 2.4 Hz), 7.22 (d, 1H, 8.1 Hz), 7.15 (dd, 1H, 9.0 Hz and 2.4 Hz), 3.99 (s, 3H), 3.22-3.10 (m, 2H), $2.85(\mathrm{~m}, 1 \mathrm{H}), 2.45(\mathrm{~m}, 1 \mathrm{H}), 1.78(\mathrm{~s}, 3 \mathrm{H})$; IR (v, $\left.\mathrm{cm}^{-1}\right): 2231(\mathrm{CN})$; LC-MS: $m / z=238\left(\mathrm{MH}^{+}\right)$

4.10. 2-(8-Methoxy-2,3-dihydro-1H-cyclopenta[a]naphthalen-1-ylidene)acetonitrile (15).

Dry THF $(5 \mathrm{~mL})$ was added at $-10{ }^{\circ} \mathrm{C}$ to sodium hydride $60 \%(1.8 \mathrm{~g}, 4.4 \mathrm{mmol})$ under argon. A solution of diethyl cyanomethylphosphonate $(7.1 \mathrm{~mL}, 44 \mathrm{mmol})$ in dry THF $(10 \mathrm{~mL})$ was then added dropwise. The mixture was stirred under argon until precipitation of the ylure and the solution of compound $\mathbf{1 0}(2.13 \mathrm{~g}, 10.04 \mathrm{mmol})$ in THF (10 mL) was added dropwise. The mixture was stirred for $16 \mathrm{~h}$, and then hydrolyzed. The formed solid was filtered, dissolved in diethyl ether, dried over $\mathrm{MgSO}_{4}$, filtered and concentrated under reduced pressure. Recrystallization from toluene afford $\mathbf{1 5}(50 \%)$ as a white solid; mp $135-137{ }^{\circ} \mathrm{C} ;{ }^{1} \mathrm{H}$ NMR (300 MHz, $\left.\mathrm{CDCl}_{3}\right) \delta: 7.83(\mathrm{~d}, 1 \mathrm{H}, 9.0 \mathrm{~Hz}), 7.81(\mathrm{~d}, 1 \mathrm{H}, 8.1 \mathrm{~Hz}), 7.49$ (d, 1H, $\left.2.4 \mathrm{~Hz}\right)$, $7.32(\mathrm{~d}, 1 \mathrm{H}, 8.1 \mathrm{~Hz}), 7.20(\mathrm{dd}, 1 \mathrm{H}, 9.0 \mathrm{~Hz}$ and $2.4 \mathrm{~Hz}), 6.02(\mathrm{~m}, 1 \mathrm{H}), 3.98(\mathrm{~s}, 3 \mathrm{H}), 3.31-3.19$ $(\mathrm{m}, 4 \mathrm{H}) ; \mathrm{IR}\left(\mathrm{v}, \mathrm{cm}^{-1}\right): 2228(\mathrm{CN}) ; \mathrm{LC}-\mathrm{MS}: \mathrm{m} / z=236\left(\mathrm{MH}^{+}\right)$.

\subsection{2-(8-Methoxy-2,3-dihydro-1H-cyclopenta[a]naphthalen-1-yl)acetonitrile (16).}

This compound was obtained from 15 in $75 \%$ yield as described for 13 ; mp $82-84{ }^{\circ} \mathrm{C}$ (methanol); ${ }^{1} \mathrm{H}$ NMR (300 MHz, $\left.\mathrm{CDCl}_{3}\right) \delta: 7.79$ (d, 1H, $\left.9.0 \mathrm{~Hz}\right), 7.69$ (d, 1H, 8.1 Hz), 7.27 (d, 1H, 8.1 Hz), $7.13(\mathrm{dd}, 1 \mathrm{H}, 9.0 \mathrm{~Hz}$ and $2.4 \mathrm{~Hz}), 7.02(\mathrm{~d}, 1 \mathrm{H}, 2.4 \mathrm{~Hz}), 4.01(\mathrm{~m}, 1 \mathrm{H}), 3.96(\mathrm{~s}$, $3 \mathrm{H}), 3.29(\mathrm{~m}, 1 \mathrm{H}), 3.06(\mathrm{~m}, 1 \mathrm{H}), 2.83(\mathrm{~m}, 1 \mathrm{H}), 2.61-2.45(\mathrm{~m}, 2 \mathrm{H}), 2.31(\mathrm{~m}, 1 \mathrm{H}) ; \mathrm{IR}\left(\mathrm{v}, \mathrm{cm}^{-1}\right)$ : $2241(\mathrm{CN})$; LC-MS: $m / z=238\left(\mathrm{MH}^{+}\right)$. 
4.12. 8-Methoxy-2,3-dihydro-1H-cyclopenta[a]naphthalen-1-yl)methylamine hydrochloride (17).

An $\mathrm{NH}_{3}$-saturated solution of $\mathbf{1 3}(1.12 \mathrm{~g}, 5 \mathrm{mmol})$ in $60 \mathrm{~mL}$ of ethanol was hydrogenated over Raney nickel under pressure $(50$ bars $)$ at $60{ }^{\circ} \mathrm{C}$ for $16 \mathrm{~h}$. After filtration and evaporation of ethanol, the oil was dissolved in ether, washed with water, dried over $\mathrm{MgSO}_{4}$ and treated with gaseous $\mathrm{HCl}$. The obtained solid was filtered to give $17(79 \%)$ as a white solid; mp 247-248 ${ }^{\circ} \mathrm{C} ;{ }^{1} \mathrm{H}$ NMR $\left(300 \mathrm{MHz}, \mathrm{CDCl}_{3}\right.$ ) $\delta: 8.42$ (br s, $3 \mathrm{H}$ ), 7.82 (d, $1 \mathrm{H}, 9.0$ Hz), 7.70 (d, 1H, $8.20 \mathrm{~Hz}), 7.25$ (d, 1H, $8.20 \mathrm{~Hz}), 7.18$ (d, 1H, 2.4 Hz), 7.10 (dd, 1H, 9.0 Hz and $2.4 \mathrm{~Hz}), 3.99(\mathrm{~m}, 1 \mathrm{H}), 3.93(\mathrm{~s}, 3 \mathrm{H}), 3.15-3.06(\mathrm{~m}, 2 \mathrm{H}), 2.92(\mathrm{~m}, 1 \mathrm{H}), 2.72(\mathrm{~m}, 1 \mathrm{H}), 2.39$ $(\mathrm{m}, 1 \mathrm{H}), 2.18(\mathrm{~m}, 1 \mathrm{H}) ; \mathrm{IR}\left(\mathrm{v}, \mathrm{cm}^{-1}\right): 3200-2800\left(\mathrm{NH}_{3}{ }^{+} \mathrm{Cl}^{-}\right) ;{ }^{13} \mathrm{C}$ NMR $\left(75 \mathrm{MHz}, \mathrm{DMSO}-d_{6}\right) \delta$ : 163.1, 146.8, 142.2, 135.8, 135.4, 133.0 (2C), 126.0, 122.5, 107.8, 61.1, 46.7, 46.0, 36.1, 33.5; LC-MS: $m / z=228\left(\mathrm{MH}^{+}\right)$.

4.13. 2-(8-Methoxy-2,3-dihydro-1H-cyclopenta[a]naphthalen-1-yl) ethylamine (18).

Amine 18 was obtained from 16 in $65 \%$ yield as described for compound $17 ;{ }^{1} \mathrm{H}$ NMR $\left(300 \mathrm{MHz}, \mathrm{CDCl}_{3}\right) \delta: 8.52($ br s, $2 \mathrm{H}), 7.75(\mathrm{~d}, 1 \mathrm{H}, 8.7 \mathrm{~Hz}), 7.61(\mathrm{~d}, 1 \mathrm{H}, 8.1 \mathrm{~Hz}), 7.24(\mathrm{~d}, 1 \mathrm{H}$, $8.1 \mathrm{~Hz}), 7.20(\mathrm{~d}, 1 \mathrm{H}, 2.4 \mathrm{~Hz}), 7.08(\mathrm{dd}, 1 \mathrm{H}, 8.7 \mathrm{~Hz}$ and $2.4 \mathrm{~Hz}), 3.93(\mathrm{~s}, 3 \mathrm{H}), 3.76(\mathrm{~m}, 1 \mathrm{H})$, 3.41-2.85 (m, 6H), 2.42-2.07 (m, 2H); LC-MS: $m / z=242\left(\mathrm{MH}^{+}\right)$.

4.14. (8-Methoxy-1-methyl-2,3-dihydro-1H-cyclopenta[a]naphthalen-1-yl)methylamine (19).

Amine 19 was obtained from 14 in $93 \%$ yield as described for compound 17; mp 70-72 ${ }^{\circ} \mathrm{C} ;{ }^{1} \mathrm{H}$ NMR $\left(300 \mathrm{MHz}, \mathrm{CDCl}_{3}\right) \delta: 8.42(\mathrm{br} \mathrm{s}, 2 \mathrm{H}), 7.76(\mathrm{~d}, 1 \mathrm{H}, 9.0 \mathrm{~Hz}), 7.62(\mathrm{~d}, 1 \mathrm{H}, 8.2 \mathrm{~Hz})$, $7.40(\mathrm{~d}, 1 \mathrm{H}, 2.4 \mathrm{~Hz}), 7.21(\mathrm{~d}, 1 \mathrm{H}, 8.2 \mathrm{~Hz}), 7.09(\mathrm{dd}, 1 \mathrm{H}, 9.0 \mathrm{~Hz}$ and $2.4 \mathrm{~Hz}), 3.93(\mathrm{~s}, 3 \mathrm{H})$, 3.11-2.98 (m, 4H), $2.34(\mathrm{~m}, 1 \mathrm{H}), 1.97(\mathrm{~m}, 1 \mathrm{H}), 1.54(\mathrm{~s}, 3 \mathrm{H})$; IR $\left(\mathrm{v}, \mathrm{cm}^{-1}\right): 3290\left(\mathrm{NH}_{2}\right)$; LCMS: $m / z=242\left(\mathrm{MH}^{+}\right)$.

4.15. (E)-Ethyl-3-(2-methoxyquinolin-7-yl)prop-2-enoate (5). 
This product was obtained from commercially 7-bromo-2-methoxyquinoline (3) as described for compound (4). The crude product was purified by flash chromatography (cyclohexane/EtOAc : 5/5) to afford 5 (93\%) as a white solid; mp 105-107 ${ }^{\circ} \mathrm{C} ;{ }^{1} \mathrm{H}$ NMR (300 $\left.\mathrm{MHz}, \mathrm{CDCl}_{3}\right) \delta: 7.99(\mathrm{~s}, 1 \mathrm{H}), 7.96(\mathrm{~d}, 1 \mathrm{H}, 8.7 \mathrm{~Hz}), 7.84(\mathrm{~d}, 1 \mathrm{H}, 16.2 \mathrm{~Hz}), 7.71(\mathrm{~d}, 1 \mathrm{H}, 8.4$ Hz), 7.55 (d, 1H, 8.4 Hz), $6.93(\mathrm{~d}, 1 \mathrm{H}, 8.7 \mathrm{~Hz}), 6.60$ (d, 1H, $16.2 \mathrm{~Hz}), 4.30$ (q, 2H, 7.2 Hz), $4.09(\mathrm{~s}, 3 \mathrm{H}), 1.37(\mathrm{t}, 3 \mathrm{H}, 7.2 \mathrm{~Hz}) ;{ }^{13} \mathrm{C} \mathrm{NMR}\left(75 \mathrm{MHz}, \mathrm{DMSO}-d_{6}\right) \delta: 166.9,162.9,146.7$, $144.3,138.2,135.5,128.1,128.0,126.1,122.3,119.4,114.1,60.6,53.5,14.3 ; \mathrm{IR}\left(\mathrm{v}, \mathrm{cm}^{-1}\right)$ : $1700(\mathrm{C}=\mathrm{O}) ; \mathrm{LC}-\mathrm{MS}: \mathrm{m} / z=258\left(\mathrm{MH}^{+}\right)$.

4.16. Ethyl 3-(2-methoxyquinolin-7-yl)propanoate (7).

This product was obtained from $\mathbf{5}$ as described for compound $\mathbf{6}$. The crude product was purified by flash chromatography (cyclohexane/ $\left.\mathrm{CH}_{2} \mathrm{Cl}_{2}: 9 / 1\right)$ to afford $7(80 \%)$ as a white solid; mp 91-93 ${ }^{\circ} \mathrm{C} ;{ }^{1} \mathrm{H}$ NMR $\left(300 \mathrm{MHz}, \mathrm{CDCl}_{3}\right) \delta: 7.94(\mathrm{~d}, 1 \mathrm{H}, 8.7 \mathrm{~Hz}), 7.70(\mathrm{~d}, 1 \mathrm{H}, 2.4 \mathrm{~Hz})$, $7.64(\mathrm{~d}, 1 \mathrm{H}, 8.1 \mathrm{~Hz}), 7.25(\mathrm{dd}, 1 \mathrm{H}, 8.7 \mathrm{~Hz}$ and $2.4 \mathrm{~Hz}), 6.86$ (d, 1H, 8.1 Hz), 4.15 (q, 2H, 7.2 $\mathrm{Hz}), 4.08(\mathrm{~s}, 3 \mathrm{H}), 3.13(\mathrm{t}, 2 \mathrm{H}, 7.5 \mathrm{~Hz}), 2.73(\mathrm{t}, 2 \mathrm{H}, 7.5 \mathrm{~Hz}), 1.25(\mathrm{t}, 3 \mathrm{H}, 7.2 \mathrm{~Hz}) ;{ }^{13} \mathrm{C}$ NMR $(75$ MHz, DMSO- $\left.d_{6}\right) \delta: 172.3,162.8,146.2,140.3,137.2,128.8,128.1,126.3,122.3,113.4,61.6$, 53.6, 34.1, 30.5, 14.3; IR (v, $\left.\mathrm{cm}^{-1}\right): 1715(\mathrm{CO})$; LC-MS: $\mathrm{m} / z=260\left(\mathrm{MH}^{+}\right)$.

4.17. 3-(2-Methoxyquinolin-7-yl)propanoic acid (9).

This product was obtained from $\mathbf{7}$ as described for compound (8). The crude product was purified by flash chromatography (DCM/MeOH : 9/1) to afford $9(73 \%)$ as a white solid; mp 185-187 ${ }^{\circ} \mathrm{C} ;{ }^{1} \mathrm{H}$ NMR $\left(300 \mathrm{MHz}, \mathrm{CDCl}_{3}\right) \delta: 10.3$ (br s, $\left.1 \mathrm{H}\right), 7.95$ (d, 1H, 9.0 Hz), 7.72 (d, 1H, $2.4 \mathrm{~Hz}), 7.65(\mathrm{~d}, 1 \mathrm{H}, 8.1 \mathrm{~Hz}), 7.26(\mathrm{dd}, 1 \mathrm{H}, 9.0 \mathrm{~Hz}$ and $2.4 \mathrm{~Hz}), 6.87(\mathrm{~d}, 1 \mathrm{H}, 8.1 \mathrm{~Hz}), 4.08$ $(\mathrm{s}, 3 \mathrm{H}), 3.14(\mathrm{t}, 2 \mathrm{H}, 7.5 \mathrm{~Hz}), 2.81(\mathrm{t}, 2 \mathrm{H}, 7.5 \mathrm{~Hz}) ;{ }^{13} \mathrm{C}$ NMR $\left(75 \mathrm{MHz}, \mathrm{DMSO}-d_{6}\right) \delta: 174.3$, $162.2,146.1,139.3,136.2,128.8,127.5,126.7,121.6,112.4,53.2,35.1,30.4 ; \mathrm{IR}\left(\mathrm{v}, \mathrm{cm}^{-1}\right)$ : $1695(\mathrm{C}=\mathrm{O}) ; \mathrm{LC}-\mathrm{MS}: m / z=232\left(\mathrm{MH}^{+}\right)$.

4.18. 2-Methoxy-7,8-dihydrocyclopenta[h]quinolin-9-one (11). 
Chlorosulfonic acid $(20 \mathrm{~mL})$ was added dropwise at $0{ }^{\circ} \mathrm{C}$ to acid $9(2.31 \mathrm{~g}, 1 \mathrm{mmol})$. Stirring was maintained for $24 \mathrm{~h}$ at room temperature, and then the mixture was poured into ice and extracted twice with diethyl ether. The combined organic layers were washed with water, dried over $\mathrm{MgSO}_{4}$, filtered and concentrated under reduced pressure. The residue was purified by column chromatography $\left(\mathrm{SiO}_{2}\right.$, cyclohexane/EtOAc: $\left.7 / 3\right)$ to give $\mathbf{1 1}(84 \%)$ as a white solid; mp 155-157 ${ }^{\circ} \mathrm{C} ;{ }^{1} \mathrm{H}$ NMR $\left(300 \mathrm{MHz}, \mathrm{CDCl}_{3}\right) \delta: 7.99(\mathrm{~d}, 1 \mathrm{H}, 8.9 \mathrm{~Hz}), 7.88(\mathrm{~d}, 1 \mathrm{H}$, $8.4 \mathrm{~Hz}), 7.39$ (d, 1H, $8.4 \mathrm{~Hz}), 6.94(\mathrm{~d}, 1 \mathrm{H}, 8.9 \mathrm{~Hz}), 4.19$ (s, 3H), 3.20 (m, 2H), 2.78 (m, 2H); ${ }^{13} \mathrm{C}$ NMR $\left(75 \mathrm{MHz}, \mathrm{DMSO}-d_{6}\right) \delta: 205.0,164.4,160.9,143.5,138.6,134.7,130.6,124.2$, 122.2, 113.1, 53.8, 37.1, 26.1; IR $\left(v, \mathrm{~cm}^{-1}\right): 1645(\mathrm{C}=\mathrm{O})$; LC-MS: $\mathrm{m} / z=214\left(\mathrm{MH}^{+}\right)$.

\subsection{2-(2-Methoxy-8,9-dihydro-7H-cyclopenta[h]quinolin-9-yl)acetonitrile (21).}

Dry THF $(5 \mathrm{~mL})$ was added at $-10{ }^{\circ} \mathrm{C}$ to sodium hydride $60 \%(0.88 \mathrm{~g}, 22 \mathrm{mmol})$ under argon. A solution of diethyl cyanomethylphosphonate $(7.1 \mathrm{~mL}, 44 \mathrm{mmol})$ in dry THF $(10 \mathrm{~mL})$ was then added dropwise. The mixture was stirred under argon until precipitation of the ylure and the solution of compound $11(2.13 \mathrm{~g}, 10.0 \mathrm{mmol})$ in THF (10 $\mathrm{mL})$ was added dropwise. The mixture was stirred for $16 \mathrm{~h}$, and then hydrolyzed with water. The formed solid was filtered, dried and used without further purification for the next step. A solution of this crude product in $60 \mathrm{~mL}$ of ethanol/dichloromethane (1/2) was stirred with palladium $10 \%$ on charcoal under hydrogen atmosphere at room temperature for $6 \mathrm{~h}$. The mixture was filtered and concentrated under reduced pressure. The crude product was purified by flash chromatography (cyclohexane/EtOAc: 9/1) to afford 21 (55\%) as a white solid; mp 66-67 ${ }^{\circ} \mathrm{C}$; ${ }^{1} \mathrm{H}$ NMR $\left(300 \mathrm{MHz}, \mathrm{CDCl}_{3}\right) \delta: 7.99(\mathrm{~d}, 1 \mathrm{H}, 8.9 \mathrm{~Hz}), 7.61$ (d, 1H, $\left.7.8 \mathrm{~Hz}\right), 7.29$ (d, 1H, 7.8 Hz), $6.87(\mathrm{~d}, 1 \mathrm{H}, 8.9 \mathrm{~Hz}), 4.08(\mathrm{~m}, 1 \mathrm{H}), 4.04(\mathrm{~s}, 3 \mathrm{H}), 3.42$ (dd, 1H, $16.5 \mathrm{~Hz}$ and $3.9 \mathrm{~Hz}), 3.29$ (m, 1H), $3.09(\mathrm{~m}, 1 \mathrm{H}), 2.99(\mathrm{dd}, 1 \mathrm{H}, 16.5 \mathrm{~Hz}$ and $8.4 \mathrm{~Hz}), 2.60(\mathrm{~m}, 1 \mathrm{H}), 2.20(\mathrm{~m}, 1 \mathrm{H})$; ${ }^{13} \mathrm{C}$ NMR (75 MHz, DMSO- $\left.d_{6}\right) \delta: 161.1,155.4,138.5,137.2,132.7,127.6,125.2,122.1$, 117.1, 111.2, 53.8, 36.1, 31.2, 30.7, 24.6; IR $\left(v, \mathrm{~cm}^{-1}\right): 2225(\mathrm{CN})$; LC-MS: $m / z=239\left(\mathrm{MH}^{+}\right)$. 
4.20. 2-(2-Methoxy-8,9-dihydro-7H-cyclopenta[h] quinolin-9-yl)acetic acid (22).

Compound 21 (1.2 g, $5 \mathrm{mmol})$ was dissolved in ethanol $(20 \mathrm{~mL})$, followed by the addition of $6 \mathrm{M}$ solution of $\mathrm{NaOH}(10 \mathrm{~mL})$. The reaction mixture was refluxed during $24 \mathrm{~h}$. After cooling to room temperature, water was added and the solution was extracted twice with diethyl ether. The aqueous solution was acidified with a $6 \mathrm{M}$ solution of $\mathrm{HCl}$. The formed solid was filtered and dried to afford $22(85 \%)$ as a white solid; mp 149-150 ${ }^{\circ} \mathrm{C}$; ${ }^{1} \mathrm{H}$ NMR $\left(300 \mathrm{MHz}, \mathrm{CDCl}_{3}\right) \delta: 8.00(\mathrm{~d}, 1 \mathrm{H}, 8.8 \mathrm{~Hz}), 7.59$ (d, 1H, $\left.8.4 \mathrm{~Hz}\right), 7.29$ (d, 1H, 8.4 Hz), 6.87 (d, 1H, $8.7 \mathrm{~Hz}), 4.20(\mathrm{~m}, 1 \mathrm{H}), 4.08(\mathrm{~s}, 3 \mathrm{H}), 3.66(\mathrm{dd}, 1 \mathrm{H}, 15.8 \mathrm{~Hz}$ and $4.0 \mathrm{~Hz}), 3.17(\mathrm{~m}, 1 \mathrm{H}), 3.05$ $(\mathrm{m}, 1 \mathrm{H}), 2.62-2.53(\mathrm{~m}, 2 \mathrm{H}), 2.08(\mathrm{~m}, 1 \mathrm{H}) ;{ }^{13} \mathrm{C}$ NMR $\left(75 \mathrm{MHz}, \mathrm{DMSO}-d_{6}\right) \delta: 177.9,162.1$, 145.6, 143.2, 139.8, 139.3, 127.0, 124. 0, 121.3, 111.6, 53.5 40.64, 38.8, 32.1, 31.5; IR (v, $\mathrm{cm}^{-}$ $\left.{ }^{1}\right): 1680(\mathrm{C}=\mathrm{O})$; LC-MS: $m / z=258\left(\mathrm{MH}^{+}\right)$.

4.21. (2-Methoxy-8,9-dihydro-7H-cyclopenta[h]quinolin-9-yl)methylamine hydrochloride (24).

To a solution of $22(0.5 \mathrm{~g}, 2 \mathrm{mmol})$ in $\mathrm{THF}(20 \mathrm{~mL})$ was added at $0{ }^{\circ} \mathrm{C}$ triethylamine $(0.42 \mathrm{~mL}, 3 \mathrm{mmol})$ and ethyl chloroformate $(0.28 \mathrm{~mL}, 3 \mathrm{mmol})$. After $1 \mathrm{~h}$ stirring, sodium azide (195 mg, $3 \mathrm{mmol}$ ) was added at $0{ }^{\circ} \mathrm{C}$ and the reaction mixture was stirred for an additional $2 \mathrm{~h}$. The mixture was hydrolyzed with water and extracted with $\mathrm{CH}_{2} \mathrm{Cl}_{2}$. The organic layer was washed with water, dried over $\mathrm{MgSO}_{4}$, filtered and concentrated under reduced pressure at cold condition. The crude product $(\mathbf{2 3})$ was dissolved in THF $(10 \mathrm{~mL})$, followed by the addition of $1 \mathrm{M}$ solution of $\mathrm{NaOH}(5 \mathrm{~mL})$. The reaction mixture was refluxed during $2 \mathrm{~h}$. A solution of $1 \mathrm{M} \mathrm{HCl}$ was added and the reaction mixture was extracted twice with diethyl ether. The aqueous phase was then basified with $2 \mathrm{M}$ solution of $\mathrm{NaOH}$ and extracted with diethyl ether. The organic layer was dried over $\mathrm{MgSO}_{4}$, filtered and treated with gaseous $\mathrm{HCl}$. The obtained solid was filtered to give $24(66 \%)$ as a white solid; mp 218$220{ }^{\circ} \mathrm{C} ;{ }^{1} \mathrm{H}$ NMR $\left(300 \mathrm{MHz}, \mathrm{CDCl}_{3}\right) \delta: 8.54$ (br s, 3H), $8.00(\mathrm{~d}, 1 \mathrm{H}, 8.94 \mathrm{~Hz}), 7.62(\mathrm{~d}, 1 \mathrm{H}$, 
$7.60 \mathrm{~Hz}), 7.32(\mathrm{~d}, 1 \mathrm{H}, 7.60 \mathrm{~Hz}), 6.85(\mathrm{~d}, 1 \mathrm{H}, 8.94 \mathrm{~Hz}), 4.00-3.93(\mathrm{~m}, 4 \mathrm{H}), 3.12-3.04(\mathrm{~m}, 2 \mathrm{H})$, $2.90(\mathrm{~m}, 1 \mathrm{H}), 2.70(\mathrm{~m}, 1 \mathrm{H}), 2.40(\mathrm{~m}, 1 \mathrm{H}), 2.16(\mathrm{~m}, 1 \mathrm{H}) ; \mathrm{IR}\left(\mathrm{v}, \mathrm{cm}^{-1}\right): 3210-2800\left(\mathrm{NH}_{3}{ }^{+} \mathrm{Cl}^{-}\right)$; ${ }^{13} \mathrm{C}$ NMR (75 MHz, DMSO-d $) \delta: 158.4,147.6,142.5,138.2,139.2,126.1,124.2,121.7$, 111.5, 53.8, 45.5, 43.1, 41.5, 32.4; LC-MS : $m / z=229\left(\mathrm{MH}^{+}\right)$.

4.22. 2-(2-Methoxy-8,9-dihydro-7H-cyclopenta[h]quinolin-9-yl)ethanamine hydrochloride (25).

To a suspension of $\mathrm{LiAlH}_{4}(0.38 \mathrm{~g}, 10 \mathrm{mmol})$ in $\mathrm{Et}_{2} \mathrm{O}(10 \mathrm{~mL})$ at $0{ }^{\circ} \mathrm{C}$ was added a solution of $\mathrm{AlCl}_{3}(1.33 \mathrm{~g}, 10 \mathrm{mmol})$ in $\mathrm{Et}_{2} \mathrm{O}(10 \mathrm{~mL})$. After 5 min stirring, a solution of 21 (0.6 g, $2.5 \mathrm{mmol})$ in $\mathrm{CH}_{2} \mathrm{Cl}_{2}(10 \mathrm{~mL})$ was added dropwise at $0{ }^{\circ} \mathrm{C}$. The resulting mixture was stirred at room temperature during $1 \mathrm{~h}$. An aqueous solution of sodium hydroxide $10 \%$ was added carefully and the mineral solid was filtered and washed with $\mathrm{Et}_{2} \mathrm{O}$. The filtrate was washed with water, dried over $\mathrm{MgSO}_{4}$ and treated with gaseous $\mathrm{HCl}$. The obtained solid was filtered to give 25 (90\%) as a white solid; mp 228-229 ${ }^{\circ} \mathrm{C} ;{ }^{1} \mathrm{H}$ NMR $\left(300 \mathrm{MHz}, \mathrm{CD}_{3} \mathrm{OD}-d_{6}\right) \delta$ : $8.10(\mathrm{~d}, 1 \mathrm{H}, 8.9 \mathrm{~Hz}), 7.65$ (d, 2H, $7.8 \mathrm{~Hz}), 7.31$ (d, 1H, $7.8 \mathrm{~Hz}), 6.89$ (d, 1H, 8.9 Hz), 4.90 (br $\mathrm{s}, 3 \mathrm{H}), 4.07(\mathrm{~s}, 3 \mathrm{H}), 3.88(\mathrm{~m}, 1 \mathrm{H}), 3.21(\mathrm{~m}, 1 \mathrm{H}), 3.12-2.95(\mathrm{~m}, 3 \mathrm{H}), 2.38(\mathrm{~m}, 2 \mathrm{H}), 2.00(\mathrm{~m}$, $2 \mathrm{H}) ;{ }^{13} \mathrm{C}$ NMR $\left(75 \mathrm{MHz}, \mathrm{DMSO}-d_{6}\right) \delta: 162.2,145.4,143.2,139.9,139.3,127.0,124.1,121.0$, 111.0, 52.5 40.6, 38.4, 32.1, 31.6, 30.9; IR $\left(v, \mathrm{~cm}^{-1}\right): 3200-2820\left(\mathrm{NH}^{3+} \mathrm{Cl}^{-}\right)$; LC-MS : $\mathrm{m} / z=$ $243\left(\mathrm{MH}^{+}\right)$

4.23. General procedure for synthesis of amides 17a-b, 18a, 19a, 24a, 25a and carbamate $17 c$.

To a solution of corresponding amine 17, 19, 24, 25 (2 mmol) in EtOAc (30 mL) and water $(10 \mathrm{~mL})$ were added $\mathrm{K}_{2} \mathrm{CO}_{3}(4 \mathrm{mmol})$ and the corresponding acid chloride $(2.2 \mathrm{mmol})$ at $0{ }^{\circ} \mathrm{C}$. The mixture was stirred at room temperature during $2 \mathrm{~h}$ and the layers were separated. The organic layer was washed with $1 \mathrm{M}$ solution of $\mathrm{HCl}$, water, dried over $\mathrm{MgSO}_{4}$, filtered and concentrated under reduced pressure. 
4.24. N-[(8-Methoxy-2,3-dihydro-1H-cyclopenta[a]naphthalen-1-yl)methyl]acetamide (17a).

The crude product was recrystallized from toluene to afford $\mathbf{1 7 a}(86 \%)$ as a white solid; mp 130-132 ${ }^{\circ} \mathrm{C} ;{ }^{1} \mathrm{H}$ NMR (300 MHz, DMSO-d $) \delta: 8.28$ (br t, $\left.1 \mathrm{H}\right), 7.79$ (d, 1H, 9.0 Hz), 7.64 (d, 1H, $8.4 \mathrm{~Hz}), 7.56(\mathrm{~d}, 1 \mathrm{H}, 2.1 \mathrm{~Hz}), 7.22(\mathrm{~d}, 1 \mathrm{H}, 8.4 \mathrm{~Hz}), 7.08$ (dd, 1H, $9.0 \mathrm{~Hz}$ and $2.1 \mathrm{~Hz})$, $3.92(\mathrm{~s}, 3 \mathrm{H}), 3.68-3.59(\mathrm{~m}, 2 \mathrm{H}), 3.12(\mathrm{~m}, 1 \mathrm{H}), 2.90(\mathrm{~m}, 1 \mathrm{H}), 2.73(\mathrm{~m}, 1 \mathrm{H}), 2.19-2.13(\mathrm{~m}, 2 \mathrm{H})$, $1.88(\mathrm{~s}, 3 \mathrm{H}) ;{ }^{13} \mathrm{C}$ NMR $\left(75 \mathrm{MHz}, \mathrm{DMSO}-d_{6}\right) \delta: 170.1,158.0,141.5,139.2,131.4,130.4$, 128.2, 127.5, 121.3, 117.6, 103.3, 55.7, 44.7, 42.0, 31.5, 29.3, 23.2; IR $\left(v, \mathrm{~cm}^{-1}\right): 3284(\mathrm{NH})$, $1639(\mathrm{C}=\mathrm{O})$; MS (APCI, pos. $30 \mathrm{~V}) \mathrm{m} / \mathrm{z}:[\mathrm{M}+\mathrm{H}]^{+}, 270.15$. HRMS $\left(\mathrm{ESI}^{+}\right): \mathrm{m} / z=$ calcd. for $\mathrm{C}_{17} \mathrm{H}_{20} \mathrm{NO}_{2}[\mathrm{M}+\mathrm{H}]^{+} 270.14886$ found: 270.14868 .

4.25. N-[2-(8-Methoxy-2,3-dihydro-1H-cyclopenta[a]naphthalen-1-yl)ethyl]acetamide (18a).

The crude product was recrystallized from toluene to afford $\mathbf{1 8 a}(76 \%)$ as a white solid; mp 141-142 ${ }^{\circ} \mathrm{C} ;{ }^{1} \mathrm{H}$ NMR (300 MHz, DMSO-d $) \delta: 8.35$ (br t, $\left.1 \mathrm{H}\right), 7.78$ (d, 1H, $\left.9.0 \mathrm{~Hz}\right), 7.58$ (d, 1H, $8.6 \mathrm{~Hz}), 7.52$ (d, 1H, 2.0 Hz), $7.22(\mathrm{~d}, 1 \mathrm{H}, 8.6 \mathrm{~Hz}), 7.08$ (dd, 1H, 9.0 Hz and 2.0 Hz), $3.95(\mathrm{~s}, 3 \mathrm{H}), 3.82(\mathrm{~m}, 1 \mathrm{H}), 3.42(\mathrm{~m}, 1 \mathrm{H}), 3.23-3.14(\mathrm{~m}, 2 \mathrm{H}), 3.05(\mathrm{~m}, 1 \mathrm{H}), 2.42(\mathrm{~m}, 1 \mathrm{H}), 2.27$ $(\mathrm{m}, 1 \mathrm{H}), 2.00-1.92(\mathrm{~m}, 2 \mathrm{H}), 1.82(\mathrm{~s}, 3 \mathrm{H}) ;{ }^{13} \mathrm{C}$ NMR $\left(75 \mathrm{MHz}, \mathrm{DMSO}-d_{6}\right) \delta: 170.1,158.0$, $141.5,139.2,131.4,130.4,128.2,127.5,121.3,117.6,103.3,54.0,46.2,43.0,33.5,32.5$, 30.8, 23.4; MS (APCI, pos. $30 \mathrm{~V}) \mathrm{m} / \mathrm{z}:[\mathrm{M}+\mathrm{H}]^{+}, 284.34$. HRMS $\left(\mathrm{ESI}^{+}\right): \mathrm{m} / \mathrm{z}=$ calcd. for $\mathrm{C}_{18} \mathrm{H}_{22} \mathrm{NO}_{2}[\mathrm{M}+\mathrm{H}]^{+} 284.16092$ found: 284.16034 .

4.26. N-[(8-Methoxy-1-methyl-2,3-dihydro-1H-cyclopenta[a]naphthalen-1-yl)methyl] acetamide (19a).

The crude product was recrystallized from cyclohexane to afford $19 \mathbf{a}(80 \%)$ as a white solid; mp 84-86 ${ }^{\circ} \mathrm{C} ;{ }^{1} \mathrm{H}$ NMR (300 MHz, DMSO-d $\left.d_{6}\right) \delta: 7.92$ (br t, $\left.1 \mathrm{H}\right), 7.69$ (d, $\left.1 \mathrm{H}, 9.0 \mathrm{~Hz}\right)$, $7.45(\mathrm{~d}, 1 \mathrm{H}, 8.7 \mathrm{~Hz}), 7.36(\mathrm{~d}, 1 \mathrm{H}, 2.1 \mathrm{~Hz}), 7.22(\mathrm{~d}, 1 \mathrm{H}, 8.7 \mathrm{~Hz}), 7.10$ (dd, 1H, 9.0 Hz and 2.1 Hz), 3.91 (s, 3H), 3.69 (dd, 1H, 13.3 Hz and 6.3 Hz), 3.41 (dd, 1H, 13.3 Hz and 6.3 Hz), 3.11- 
$3.03(\mathrm{~m}, 2 \mathrm{H}), 2.23(\mathrm{~m}, 1 \mathrm{H}), 1.78(\mathrm{~m}, 1 \mathrm{H}), 1.88(\mathrm{~s}, 3 \mathrm{H}), 1.47(\mathrm{~s}, 3 \mathrm{H}) ;{ }^{13} \mathrm{C} \mathrm{NMR}(75 \mathrm{MHz}$, DMSO- $\left.d_{6}\right) \delta: 171.0,157.6,142.1,140.2,131.4,129.5,128.2,128.0,121.3,117.3,102.9$, 55.6, 47.0, 45.2, 38.5, 29.8, 24.9, 23.2; IR $\left(v, \mathrm{~cm}^{-1}\right): 3251(\mathrm{NH}), 1624(\mathrm{C}=\mathrm{O})$; MS (APCI, pos. $30 \mathrm{~V}) \mathrm{m} / \mathrm{z}$ : $[\mathrm{M}+\mathrm{H}]^{+}$, 284.25. HRMS $\left(\mathrm{ESI}^{+}\right): m / z=$ calcd. for $\mathrm{C}_{18} \mathrm{H}_{22} \mathrm{NO}_{2}[\mathrm{M}+\mathrm{H}]^{+}$ 284.12337 found: 284.12259 .

4.27. $N$-[(2-Methoxy-8,9-dihydro-7H-cyclopenta[h] quinolin-9-yl)methyl]acetamide (24a).

The crude product was recrystallized from toluene to afford $\mathbf{2 4 a}(85 \%)$ as a white solid; mp 110-111 ${ }^{\circ} \mathrm{C} ;{ }^{1} \mathrm{H}$ NMR (300 MHz, $\left.\mathrm{CDCl}_{3}\right) \delta: 8.03(\mathrm{~d}, 1 \mathrm{H}, 8.9 \mathrm{~Hz}), 7.61$ (d, 1H, 8.0 Hz), 7.36 (br s, 1H), 7.33 (d, 1H, $8.0 \mathrm{~Hz}), 6.88(\mathrm{~d}, 1 \mathrm{H}, 8.9 \mathrm{~Hz}), 4.12(\mathrm{~s}, 3 \mathrm{H}), 4.06(\mathrm{~m}, 1 \mathrm{H}), 3.69$ (m, 1H), $3.59(\mathrm{~m}, 1 \mathrm{H}), 3.23(\mathrm{~m}, 1 \mathrm{H}), 3.00(\mathrm{~m}, 1 \mathrm{H}), 2.41(\mathrm{~m}, 1 \mathrm{H}), 2.06(\mathrm{~m}, 1 \mathrm{H}), 1.86(\mathrm{~s}, 3 \mathrm{H})$; ${ }^{13} \mathrm{C}$ NMR $\left(75 \mathrm{MHz}, \mathrm{CDCl}_{3}\right) \delta: 170.1,162.4,146.6,143.5,139.9,139.8,127.2,124.0,121.8$, 111.7, 53.5, 45.0, 42.4, 32.2, 30.6, 23.2; IR $\left(v, \mathrm{~cm}^{-1}\right): 3290(\mathrm{NH}), 1626(\mathrm{C}=\mathrm{O})$; MS (APCI, pos. $30 \mathrm{~V}) \mathrm{m} / \mathrm{z}$ : $[\mathrm{M}+\mathrm{H}]^{+}$, 271.26. HRMS $\left(\mathrm{ESI}^{+}\right): \mathrm{m} / \mathrm{z}=$ calcd. for $\mathrm{C}_{16} \mathrm{H}_{19} \mathrm{~N}_{2} \mathrm{O}_{2}[\mathrm{M}+\mathrm{H}]^{+}$ 271.1441 found: 271.14364 .

4.28. N-[2-(2-Methoxy-8,9-dihydro-7H-cyclopenta[h]quinolin-9-yl)ethyl]acetamide (25a).

The crude product was recrystallized from toluene to afford $\mathbf{2 5 a}(84 \%)$ as a white solid; mp 119-120 ${ }^{\circ} \mathrm{C} ;{ }^{1} \mathrm{H}$ NMR (300 MHz, $\left.\mathrm{CDCl}_{3}\right) \delta: 7.98(\mathrm{~d}, 1 \mathrm{H}, 8.9 \mathrm{~Hz}), 7.56(\mathrm{~d}, 1 \mathrm{H}, 8.0 \mathrm{~Hz})$, $7.28(\mathrm{~d}, 1 \mathrm{H}, 8.0 \mathrm{~Hz}), 6.85(\mathrm{~d}, 1 \mathrm{H}, 8.9 \mathrm{~Hz}), 5.81(\mathrm{br} \mathrm{s}, 1 \mathrm{H}), 4.08(\mathrm{~s}, 3 \mathrm{H}), 3.84(\mathrm{~m}, 1 \mathrm{H}), 3.46(\mathrm{~m}$, 1H), 3.33-3.16 (m, 2H), $3.00(\mathrm{~m}, 1 \mathrm{H}), 2.40(\mathrm{~m}, 1 \mathrm{H}), 2.25(\mathrm{~m}, 1 \mathrm{H}), 2.07-1.92(\mathrm{~m}, 2 \mathrm{H}), 1.89(\mathrm{~s}$, $3 \mathrm{H}) ;{ }^{13} \mathrm{C} \mathrm{NMR}\left(75 \mathrm{MHz}, \mathrm{CDCl}_{3}\right) \delta: 170.5,161.4,145.6,142.5,139.8,139.2,127.2,124.2$, 122.4, 111.5, 53.5, 45.0, 42.4, 32.2, 31.5, 30.6, 23.2; IR $\left(v, \mathrm{~cm}^{-1}\right): 3285(\mathrm{NH}), 1628(\mathrm{C}=\mathrm{O})$; MS (APCI, pos. $30 \mathrm{~V}) \mathrm{m} / \mathrm{z}:[\mathrm{M}+\mathrm{H}]^{+}$, 285.24. HRMS $\left(\mathrm{ESI}^{+}\right): \mathrm{m} / z=$ calcd. for $\mathrm{C}_{17} \mathrm{H}_{21} \mathrm{~N}_{2} \mathrm{O}_{2}$ $[\mathrm{M}+\mathrm{H}]^{+} 285.15975$ found: 285.15932 .

4.29. 2-Methoxy-N-[(8-methoxy-2,3-dihydro-1H-cyclopenta[a]naphtalen-1-yl)methyl] acetamide (17b). 
The crude product was purified by flash chromatography (cyclohexane / EtOAc : 5/5) and recrystallized from toluene to afford $\mathbf{1 7 b}(73 \%)$ as a white solid; mp $103-104{ }^{\circ} \mathrm{C} ;{ }^{1} \mathrm{H}$ NMR (300 MHz, $\left.\mathrm{CDCl}_{3}\right) \delta: 7.72(\mathrm{~d}, 1 \mathrm{H}, 8.9 \mathrm{~Hz}), 7.66(\mathrm{~d}, 1 \mathrm{H}, 8.5 \mathrm{~Hz}), 7.40$ (d, 1H, $\left.2.4 \mathrm{~Hz}\right)$, $7.26(\mathrm{~d}, 1 \mathrm{H}, 8.5 \mathrm{~Hz}), 7.11(\mathrm{dd}, 1 \mathrm{H}, 8.9 \mathrm{~Hz}$ and $2.4 \mathrm{~Hz}), 6.76(\mathrm{br} \mathrm{s}, 1 \mathrm{H}), 4.00$ (s, 3H), 3.94-3.86 $(\mathrm{m}, 4 \mathrm{H}), 3.38(\mathrm{~s}, 3 \mathrm{H}), 3.24-3.15(\mathrm{~m}, 2 \mathrm{H}), 3.00(\mathrm{~m}, 1 \mathrm{H}), 2.35(\mathrm{~m}, 1 \mathrm{H}), 2.13(\mathrm{~m}, 1 \mathrm{H}) ;{ }^{13} \mathrm{C} \mathrm{NMR}$ $\left(75 \mathrm{MHz}, \mathrm{CDCl}_{3}\right) \delta: 169.9,158.1,141.6,138.0,131.3,130.0,128.2,127.6,120.8,117.5$, 102.5, 72.0, 59.1, 55.4, 44.0, 41.8, 31.7, 29.3; IR (v, $\left.\mathrm{cm}^{-1}\right): 3318(\mathrm{NH}), 1635(\mathrm{C}=\mathrm{O})$; MS (APCI, pos. $30 \mathrm{~V}$ ) m/z: $[\mathrm{M}+\mathrm{H}]^{+}, 300.24$. HRMS $\left(\mathrm{ESI}^{+}\right): \mathrm{m} / \mathrm{z}=$ calcd. for $\mathrm{C}_{18} \mathrm{H}_{22} \mathrm{NO}_{3}[\mathrm{M}+\mathrm{H}]^{+}$ 300.15214 found: 300.15259 .

4.30. Methyl-N-[(8-methoxy-2,3-dihydro-1H-cyclopenta[a]naphthalen-1-yl)methyl] carbamate (17c).

The crude product was purified by flash chromatography (cyclohexane/EtOAc : 5/5) and recrystallized from toluene to afford $17 \mathbf{c}(88 \%)$ as a white solid; mp $76-78{ }^{\circ} \mathrm{C} ;{ }^{1} \mathrm{H}$ NMR $\left(300 \mathrm{MHz}, \mathrm{DMSO}-d_{6}\right) \delta: 7.80(\mathrm{~d}, 1 \mathrm{H}, 9.0 \mathrm{~Hz}), 7.65(\mathrm{~d}, 1 \mathrm{H}, 8.1 \mathrm{~Hz}), 7.55$ (t, 1H, $\left.5.7 \mathrm{~Hz}\right), 7.46$ (d, 1H, $2.4 \mathrm{~Hz}), 7.23(\mathrm{~d}, 1 \mathrm{H}, 8.1 \mathrm{~Hz}), 7.09(\mathrm{dd}, 1 \mathrm{H}, 9.0 \mathrm{~Hz}$ and $2.4 \mathrm{~Hz}), 3.91(\mathrm{~s}, 3 \mathrm{H}), 3.69$ (m, 1H), $3.58(\mathrm{~s}, 3 \mathrm{H}), 3.45(\mathrm{~m}, 1 \mathrm{H}), 3.08(\mathrm{~m}, 1 \mathrm{H}), 2.90(\mathrm{~m}, 1 \mathrm{H}), 2.75(\mathrm{~m}, 1 \mathrm{H}), 2.19-2.15(\mathrm{~m}, 2 \mathrm{H})$; ${ }^{13} \mathrm{C}$ NMR $\left(75 \mathrm{MHz}, \mathrm{DMSO}-d_{6}\right) \delta: 158.0,157.6,141.6,139.0,131.4,130.4,128.2,127.6$, 121.3, 117.5, 103.1, 55.6, 51.8, 44.9, 43.4, 31.4, 29.0; IR (v, $\left.\mathrm{cm}^{-1}\right): 3296(\mathrm{NH}), 1722(\mathrm{C}=\mathrm{O})$; MS (APCI, pos. $30 \mathrm{~V}) \mathrm{m} / \mathrm{z}:[\mathrm{M}+\mathrm{H}]^{+}$, 286.24. HRMS $\left(\mathrm{ESI}^{+}\right): \mathrm{m} / \mathrm{z}=$ calcd. for $\mathrm{C}_{17} \mathrm{H}_{20} \mathrm{NO}_{3}$ $[\mathrm{M}+\mathrm{H}]^{+} 286.12337$ found: 286.12359 .

\subsection{General procedure for synthesis of sulfonamide $\mathbf{1 7 d - e}$ and $\mathbf{1 9 b}$.}

To a solution of corresponding amine 17 or 19 (404 mg, $2 \mathrm{mmol})$ in $\mathrm{CH}_{2} \mathrm{Cl}_{2}(50 \mathrm{~mL})$ were added at $0{ }^{\circ} \mathrm{C}$ triethylamine $(0.70 \mathrm{~mL}, 5 \mathrm{mmol})$ and the corresponding alkyl sulfonyl chloride $(2.6 \mathrm{mmol})$. The mixture was stirred at room temperature for $2 \mathrm{~h}$ and hydrolyzed with 
water. The organic layer was washed with $1 \mathrm{M}$ solution of $\mathrm{HCl}$, water, dried over $\mathrm{MgSO}_{4}$, filtered and concentrated under reduced pressure.

4.32. N-[(8-Methoxy-2,3-dihydro-1H-cyclopenta[a]naphthalen-1-yl)methyl]methansulfonamide (17d).

The crude product was treated with diisopropyl ether and recrystallized from cyclohexane to afford $\mathbf{1 7 d}(70 \%)$ as a white solid; mp 110-112 ${ }^{\circ} \mathrm{C} ;{ }^{1} \mathrm{H}$ NMR $(300 \mathrm{MHz}$, DMSO- $\left.d_{6}\right) \delta: 7.82(\mathrm{~d}, 1 \mathrm{H}, 9.0 \mathrm{~Hz}), 7.68(\mathrm{~d}, 1 \mathrm{H}, 8.4 \mathrm{~Hz}), 7.36(\mathrm{t}, 1 \mathrm{H}, 6.3 \mathrm{~Hz}), 7.26(\mathrm{~d}, 1 \mathrm{H}, 2.1$ Hz), 7.25 (d, 1H, 8.4 Hz), 7.09 (dd, 1H, $9.0 \mathrm{~Hz}$ and $2.1 \mathrm{~Hz}), 3.89(\mathrm{~s}, 3 \mathrm{H}), 3.72(\mathrm{~m}, 1 \mathrm{H}), 3.31$ $(\mathrm{m}, 1 \mathrm{H}), 3.11(\mathrm{~m}, 1 \mathrm{H}), 2.93(\mathrm{~m}, 1 \mathrm{H}), 2.87(\mathrm{~s}, 3 \mathrm{H}), 2.82(\mathrm{~m}, 1 \mathrm{H}), 2.25-2.21(\mathrm{~m}, 2 \mathrm{H}) ;{ }^{13} \mathrm{C} \mathrm{NMR}$ $\left(75 \mathrm{MHz}, \mathrm{DMSO}-d_{6}\right) \delta: 158.0,142.0,138.5,131.2,130.5,128.2,127.8,121.4,117.6,103.0$, 55.6, 45.4, 45.3, 40.1, 31.5, 28.9; IR $\left(v, \mathrm{~cm}^{-1}\right): 3294(\mathrm{NH})$; LC-MS : $\mathrm{m} / z=306\left(\mathrm{MH}^{+}\right) . \mathrm{MS}$ (APCI, pos. $30 \mathrm{~V}$ ) m/z: $[\mathrm{M}+\mathrm{H}]^{+}, 306.27$. $\mathrm{HRMS}\left(\mathrm{ESI}^{+}\right): \mathrm{m} / z=$ calcd. for $\mathrm{C}_{16} \mathrm{H}_{20} \mathrm{NO}_{3} \mathrm{~S}[\mathrm{M}+\mathrm{H}]^{+}$ 306.14312 found: 306.14372 .

4.33. N-[(8-Methoxy-2,3-dihydro-1H-cyclopenta[a]naphthalen-1-yl)methyl]ethansulfonamide (17e).

The crude product was recrystallized from cyclohexane to afford $\mathbf{1 7 e}(70 \%)$ as a white solid; mp 109-110 ${ }^{\circ} \mathrm{C} ;{ }^{1} \mathrm{H}$ NMR (300 MHz, DMSO- $\left.d_{6}\right) \delta: 7.82(\mathrm{~d}, 1 \mathrm{H}, 9.0 \mathrm{~Hz}), 7.67(\mathrm{~d}, 1 \mathrm{H}$, $8.4 \mathrm{~Hz}), 7.41$ (t, 1H, $6.3 \mathrm{~Hz}), 7.26$ (d, 1H, $2.7 \mathrm{~Hz}), 7.25$ (d, 1H, 8.4 Hz), 7.09 (dd, 1H, 9.0 Hz and $2.7 \mathrm{~Hz}), 3.89(\mathrm{~s}, 3 \mathrm{H}), 3.71(\mathrm{~m}, 1 \mathrm{H}), 3.27(\mathrm{~m}, 1 \mathrm{H}), 3.16-2.74(\mathrm{~m}, 5 \mathrm{H}), 2.23-2.17(\mathrm{~m}, 2 \mathrm{H})$, $1.16(\mathrm{t}, 3 \mathrm{H}, 7.5 \mathrm{~Hz}) ;{ }^{13} \mathrm{C}$ NMR $\left(75 \mathrm{MHz}, \mathrm{DMSO}-d_{6}\right) \delta: 158.0,142.0,138.5,131.2,130.5$, 128.2, 127.8, 121.4, 117.6, 103.0, 55.6, 46.1, 45.6, 45.3, 31.4, 28.8, 8.6; IR (v, cm $\left.{ }^{-1}\right): 3298$ $(\mathrm{NH})$; MS (APCI, pos. $30 \mathrm{~V}) \mathrm{m} / \mathrm{z}:[\mathrm{M}+\mathrm{H}]^{+}$, 320.27. HRMS $\left(\mathrm{ESI}^{+}\right): m / z=$ calcd. for $\mathrm{C}_{17} \mathrm{H}_{22} \mathrm{NO}_{3} \mathrm{~S}[\mathrm{M}+\mathrm{H}]^{+} 320.15232$ found: 320.15254 .

4.34. N-[(8-Methoxy-1-methyl-2,3-dihydro-1H-cyclopenta[a]naphtalen-1-yl)methyl]methane sulfonamide (19b). 
The crude product was recrystallized from cyclohexane to afford $\mathbf{1 9 b}(50 \%)$ as a white solid; mp 98-100 ${ }^{\circ} \mathrm{C} ;{ }^{1} \mathrm{H}$ NMR $\left(300 \mathrm{MHz}, \mathrm{DMSO}-d_{6}\right) \delta: 7.82(\mathrm{~d}, 1 \mathrm{H}, 9.0 \mathrm{~Hz}), 7.68(\mathrm{~d}, 1 \mathrm{H}, 8.1$ Hz),7.39 (d, 1H, 1.8 Hz), 7.21 (d, 1H, 8.1 Hz),7.11 (dd, 1H, 9.0 Hz and 1.8 Hz),7.03 (t, 1H, $6.9 \mathrm{~Hz}), 3.88$ (s, 3H), $3.42(\mathrm{dd}, 1 \mathrm{H}, 13.2 \mathrm{~Hz}$ and $6.9 \mathrm{~Hz}), 3.26(\mathrm{dd}, 1 \mathrm{H}, 13.2 \mathrm{~Hz}$ and $6.9 \mathrm{~Hz})$, 2.97-2.94 (m, 2H), $2.77(\mathrm{~s}, 3 \mathrm{H}), 2.38(\mathrm{~m}, 1 \mathrm{H}), 1.83(\mathrm{~m}, 1 \mathrm{H}), 1.56(\mathrm{~s}, 3 \mathrm{H}) ;{ }^{13} \mathrm{C} \mathrm{NMR}(75 \mathrm{MHz}$, DMSO- $\left.d_{6}\right) \delta: 157.4,142.7,140.8,131.3,131.0,129.0,128.3,121.6,116.9,103.1,55.4,50.5$, 50.2, 39.8, 38.1, 30.6, 25.0; IR $\left(v, \mathrm{~cm}^{-1}\right): 3297(\mathrm{NH})$; MS (APCI, pos. $\left.30 \mathrm{~V}\right) \mathrm{m} / \mathrm{z}:[\mathrm{M}+\mathrm{H}]^{+}$, 320.24. HRMS $\left(\mathrm{ESI}^{+}\right): m / z=$ calcd. for $\mathrm{C}_{17} \mathrm{H}_{22} \mathrm{NO}_{3} \mathrm{~S}[\mathrm{M}+\mathrm{H}]^{+} 320.12328$ found: 320.12247 . 4.35. $N^{1}$-[(8-Methoxy-2,3-dihydro-1H-cyclopenta[a]naphthalen-1-yl)methyl]urea (17f).

To a solution of amine $17(0.45 \mathrm{~g}, 2 \mathrm{mmol})$ in water $(10 \mathrm{~mL})$ and $1 \mathrm{M}$ solution of $\mathrm{HCl}$ $(1 \mathrm{~mL})$ was added potassium cyanate $(0.2 \mathrm{~g}, 2.5 \mathrm{mmol})$. The mixture was stirred at room temperature during $24 \mathrm{~h}$ ). The solid was filtered, washed with water and recrystallized from acetonitrile to afford $\mathbf{1 7 f}(84 \%)$ as a white solid; mp $173-175{ }^{\circ} \mathrm{C} ;{ }^{1} \mathrm{H}$ NMR $(300 \mathrm{MHz}$, DMSO- $\left.d_{6}\right) \delta: 7.79(\mathrm{~d}, 1 \mathrm{H}, 8.97 \mathrm{~Hz}), 7.64(\mathrm{~d}, 1 \mathrm{H}, 8.20 \mathrm{~Hz}), 7.56(\mathrm{~d}, 1 \mathrm{H}, 2.4 \mathrm{~Hz}), 7.23(\mathrm{~d}, 1 \mathrm{H}$, 8.2 Hz), 7.00 (dd, 1H, $8.97 \mathrm{~Hz}$ and 2.4 Hz), 6.26 (br t, 1H, $6 \mathrm{~Hz}), 5.51$ (br s, 2H), 3.90 (s, 3H), $3.67(\mathrm{~m}, 1 \mathrm{H}), 3.49(\mathrm{~m}, 1 \mathrm{H}), 3.11(\mathrm{~m}, 1 \mathrm{H}), 2.89(\mathrm{~m}, 1 \mathrm{H}), 2.76(\mathrm{~m}, 1 \mathrm{H}), 2.19-2.09(\mathrm{~m}, 2 \mathrm{H})$; ${ }^{13} \mathrm{C}$ NMR $\left(75 \mathrm{MHz}, \mathrm{DMSO}-d_{6}\right) \delta: 160.5,155.7,141.1,138.5,130.5,130.0,127.1,128.5$, 121.4, 118.2, 102.5, 55.8, 46.2, 44.2, 31.4, 29.1; IR (v, cm $\left.{ }^{-1}\right): 3425\left(\mathrm{NH}_{2}\right), 3340(\mathrm{NH}), 1625$ $(\mathrm{C}=\mathrm{O})$; MS (APCI, pos. $30 \mathrm{~V}) \mathrm{m} / \mathrm{z}:[\mathrm{M}+\mathrm{H}]^{+}, 271.23 . \mathrm{HRMS}\left(\mathrm{ESI}^{+}\right): \mathrm{m} / \mathrm{z}=$ calcd. for $\mathrm{C}_{16} \mathrm{H}_{19} \mathrm{~N}_{2} \mathrm{O}_{2}[\mathrm{M}+\mathrm{H}]^{+} 271.12418$ found: 320.12357 .

4.36. $N^{1}$-[(8-Methoxy-2,3-dihydro-1H-cyclopenta[a]naphthalen-1-yl)methyl]- $N^{3}$-methyl-urea $(17 g)$.

To a solution of amine $17(1.93 \mathrm{~g}, 8.49 \mathrm{mmol})$ in DMSO (50 $\mathrm{mL})$ were added triethylamine $(1.77 \mathrm{~mL}, 12.74 \mathrm{mmol})$ and then $N$-methylphenylcarbamate $(1.92 \mathrm{~g}, 12.74$ mmol). The mixture was stirred at $60{ }^{\circ} \mathrm{C}$ during $3 \mathrm{~h}$ then, hydrolyzed and extracted with ethyl 
acetate. The organic layer was washed with $1 \mathrm{M}$ solution of $\mathrm{HCl}$, water, dried over $\mathrm{MgSO}_{4}$, filtered and concentrated under reduced pressure. The crude product was recrystallized from toluene to afford $\mathbf{1 7 g}(68 \%)$ as a white solid; mp 160-161 ${ }^{\circ} \mathrm{C} ;{ }^{1} \mathrm{H}$ NMR (300 MHz, DMSO- $\left.d_{6}\right)$ $\delta: 7.79(\mathrm{~d}, 1 \mathrm{H}, 9.0 \mathrm{~Hz}), 7.64(\mathrm{~d}, 1 \mathrm{H}, 8.1 \mathrm{~Hz}), 7.53(\mathrm{~d}, 1 \mathrm{H}, 2.1 \mathrm{~Hz}), 7.22(\mathrm{~d}, 1 \mathrm{H}, 8.1 \mathrm{~Hz}), 7.07$ (dd, 1H, 9.0 Hz and 2.1 Hz), $6.23(\mathrm{br} t, 1 \mathrm{H}), 5.79$ (q, 1H, $5.4 \mathrm{~Hz}), 3.91(\mathrm{~s}, 3 \mathrm{H}), 3.69(\mathrm{~m}, 1 \mathrm{H})$, $3.52(\mathrm{~m}, 1 \mathrm{H}), 3.11(\mathrm{~m}, 1 \mathrm{H}), 2.91-2.74(\mathrm{~m}, 2 \mathrm{H}), 2.59(\mathrm{~d}, 3 \mathrm{H}, 4.5 \mathrm{~Hz}), 2.14-2.10(\mathrm{~m}, 2 \mathrm{H})$; ${ }^{13} \mathrm{C}$ NMR $\left(75 \mathrm{MHz}, \mathrm{DMSO}-d_{6}\right) \delta: 159.5,157.9,141.6,139.5,131.5,130.3,128.2,127.4$, 121.3, 117.5, 103.5, 55.6, 45.3, 42.8, 31.6, 29.2, 26.9; IR (v, $\left.\mathrm{cm}^{-1}\right): 3333(\mathrm{NH}), 1624(\mathrm{C}=\mathrm{O})$;

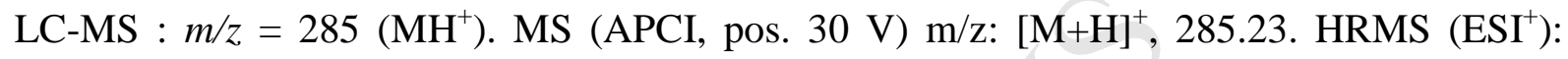
$m / z=$ calcd. for $\mathrm{C}_{17} \mathrm{H}_{21} \mathrm{~N}_{2} \mathrm{O}_{2}[\mathrm{M}+\mathrm{H}]^{+} 285.12416$ found: 285.12346 .

4.37. General procedure for synthesis of alkyl urea $17 \mathbf{h}-\mathbf{i}, \mathbf{1 9 c - d}, \mathbf{2 4 b - c}$ and thiourea $17 \mathbf{k}-\mathbf{m}$, 19e-g and 24b.

To a solution of corresponding amine 17, 18, 19 or $24(1 \mathrm{mmol})$ in $\mathrm{CH}_{2} \mathrm{Cl}_{2}(10 \mathrm{~mL})$ were added triethylamine $(2 \mathrm{mmol})$ and the corresponding alkyl isocyanate or isothiocyanate $(1.2 \mathrm{mmol})$ at $0{ }^{\circ} \mathrm{C}$. The mixture was stirred at room temperature during $2 \mathrm{~h}$ and hydrolyzed. $\mathrm{CH}_{2} \mathrm{Cl}_{2}$ was added and the organic layer was washed with a $1 \mathrm{M}$ solution of $\mathrm{HCl}$ and water, dried over $\mathrm{MgSO}_{4}$, filtered and concentrated under reduced pressure.

4.38. $\quad N^{1}$-Ethyl-N $N^{3}$-[(8-methoxy-2,3-dihydro-1H-cyclopenta[a]naphtalen-1-yl)methyl]urea (17h).

The crude product was purified by flash chromatography (cyclohexane/EtOAc : 5/5) and recrystallized from toluene to afford $\mathbf{1 7 h}(57 \%)$ as a white solid; mp $148-150{ }^{\circ} \mathrm{C} ;{ }^{1} \mathrm{H}$ NMR $\left(300 \mathrm{MHz}\right.$, DMSO- $\left.d_{6}\right) \delta: 7.79(\mathrm{~d}, 1 \mathrm{H}, 9.0 \mathrm{~Hz}), 7.65(\mathrm{~d}, 1 \mathrm{H}, 8.1 \mathrm{~Hz}), 7.51(\mathrm{~d}, 1 \mathrm{H}$, $2.4 \mathrm{~Hz}), 7.23(\mathrm{~d}, 1 \mathrm{H}, 8.1 \mathrm{~Hz}), 7.08(\mathrm{dd}, 1 \mathrm{H}, 9.0 \mathrm{~Hz}$ and $2.4 \mathrm{~Hz}), 6.11(\mathrm{t}, 1 \mathrm{H}, 6.0 \mathrm{~Hz}), 5.84$ (t, 1H, 5.4 Hz), $3.91(\mathrm{~s}, 3 \mathrm{H}), 3.67(\mathrm{~m}, 1 \mathrm{H}), 3.51(\mathrm{~m}, 1 \mathrm{H}), 3.13-3.00(\mathrm{~m}, 3 \mathrm{H}), 2.93-2.74(\mathrm{~m}, 2 \mathrm{H})$, 2.15-2.10 (m, 2H) , $1.00(\mathrm{t}, 3 \mathrm{H}, 7.2 \mathrm{~Hz}) ;{ }^{13} \mathrm{C}$ NMR (75 MHz, DMSO-d $\left.d_{6}\right) \delta: 158.8,157.9$, 
$141.6,139.5,131.5,130.3,128.2,127.4,121.3,117.5,103.6,55.6,45.3,42.7,34.6,31.6$, 29.2, 16.2; IR $\left(v, \mathrm{~cm}^{-1}\right): 3317(\mathrm{NH}), 1622(\mathrm{C}=\mathrm{O})$; MS (APCI, pos. $\left.30 \mathrm{~V}\right) \mathrm{m} / \mathrm{z}:[\mathrm{M}+\mathrm{H}]^{+}$, 300.21. HRMS $\left(\mathrm{ESI}^{+}\right): \mathrm{m} / z=$ calcd. for $\mathrm{C}_{18} \mathrm{H}_{23} \mathrm{~N}_{2} \mathrm{O}_{2}[\mathrm{M}+\mathrm{H}]^{+} 300.16812$ found: 300.16734 .

4.39. $N^{1}$-[(8-Methoxy-2,3-dihydro-1H-cyclopenta[a]naphtalen-1-yl)methyl]-N ${ }^{3}$-propylurea (17i).

The crude product was purified by flash chromatography (cyclohexane/EtOAc : 5/5) and recrystallized from toluene to afford $\mathbf{1 7 i}(77 \%)$ as a white solid; mp $139-141{ }^{\circ} \mathrm{C} ;{ }^{1} \mathrm{H}$ NMR $\left(300 \mathrm{MHz}, \mathrm{DMSO}-d_{6}\right) \delta: 7.79$ (d, 1H, $\left.9.0 \mathrm{~Hz}\right), 7.64$ (d, 1H, $\left.8.1 \mathrm{~Hz}\right), 7.50$ (d, 1H, $\left.2.4 \mathrm{~Hz}\right), 7.23$ (d, 1H, 8.1 Hz), $7.08(\mathrm{dd}, 1 \mathrm{H}, 9.0 \mathrm{~Hz}$ and $2.4 \mathrm{~Hz}), 6.10(\mathrm{t}, 1 \mathrm{H}, 6.0 \mathrm{~Hz}), 5.90(\mathrm{t}, 1 \mathrm{H}, 5.7 \mathrm{~Hz})$, $3.91(\mathrm{~s}, 3 \mathrm{H}), 3.68(\mathrm{~m}, 1 \mathrm{H}), 3.51(\mathrm{~m}, 1 \mathrm{H}), 3.08(\mathrm{~m}, 1 \mathrm{H}), 2.96(\mathrm{q}, 2 \mathrm{H}, 6.6 \mathrm{~Hz}), 2.92-2.76(\mathrm{~m}$, 2H), 2.16-2.10 (m, 2H), $1.38(\mathrm{~m}, 2 \mathrm{H}), 0.84(\mathrm{t}, 3 \mathrm{H}, 6.6 \mathrm{~Hz}) ;{ }^{13} \mathrm{C}$ NMR $\left(75 \mathrm{MHz}, \mathrm{DMSO}-d_{6}\right) \delta$ : $158.8,158.0,141.8,139.3,131.7,130.3,128.2,127.5,121.3,117.8,103.8,56.0,46.2,45.6$, 44.0, 31.4, 28.8, 22.5, 11.9; IR (v, $\left.\mathrm{cm}^{-1}\right): 3294(\mathrm{NH}), 1623(\mathrm{C}=\mathrm{O})$; MS (APCI, pos. $\left.30 \mathrm{~V}\right)$ m/z: $[\mathrm{M}+\mathrm{H}]^{+}, 313.25$. HRMS $\left(\mathrm{ESI}^{+}\right): m / z=$ calcd. for $\mathrm{C}_{19} \mathrm{H}_{25} \mathrm{~N}_{2} \mathrm{O}_{2}[\mathrm{M}+\mathrm{H}]^{+} 313.18377$ found: 313.18334.

4.40. $\quad N^{1}$-Ethyl-N $N^{3}-[(8-m e t h o x y-1-m e t h y l-2,3-d i h y d r o-1 H$-cyclopenta[a]naphthalen-1-yl) methyl]urea $(\mathbf{1 9 c})$.

The crude product was purified by flash chromatography (cyclohexane/EtOAc : 5/5) and recrystallized from toluene to afford 19c (67\%) as a white solid; mp 143-145 ${ }^{\circ} \mathrm{C} ;{ }^{1} \mathrm{H}$ NMR (300 MHz, DMSO- $\left.d_{6}\right) \delta: 7.82(\mathrm{~d}, 1 \mathrm{H}, 9.0 \mathrm{~Hz}), 7.66(\mathrm{~d}, 1 \mathrm{H}, 8.1 \mathrm{~Hz}), 7.40(\mathrm{~d}, 1 \mathrm{H}, 2.4$ Hz), 7.20 (d, 1H, 8.1 Hz), 7.09 (dd, 1H, 9.0 Hz and 2.4 Hz), 5.83 (br t, 1H, 5.4 Hz), 5.64 (br t, 1H, $6.3 \mathrm{~Hz}), 3.88(\mathrm{~s}, 3 \mathrm{H}), 3.71(\mathrm{dd}, 1 \mathrm{H}, 13.5 \mathrm{~Hz}$ and $6.3 \mathrm{~Hz}), 3.36(\mathrm{dd}, 1 \mathrm{H}, 13.5 \mathrm{~Hz}$ and 6.3 $\mathrm{Hz}), 3.01-2.98(\mathrm{~m}, 4 \mathrm{H}), 2.24(\mathrm{~m}, 1 \mathrm{H}), 1.78(\mathrm{~m}, 1 \mathrm{H}), 1.47(\mathrm{~s}, 3 \mathrm{H}), 0.92(\mathrm{t}, 3 \mathrm{H}, 7.2 \mathrm{~Hz})$; ${ }^{13} \mathrm{C}$ NMR (75 MHz, DMSO- $\left.d_{6}\right) \delta$ : 158.8, 157.4, 142.6, 141.2, 131.4, 131.0, 129.0, 128.0, $121.6,116.9,102.9,55.5,47.1,45.9,38.2,34.5,30.7,24.9,16.1 ; \mathrm{IR}\left(v, \mathrm{~cm}^{-1}\right): 3279(\mathrm{NH})$, 
$1623(\mathrm{C}=\mathrm{O})$; MS (APCI, pos. $30 \mathrm{~V}) \mathrm{m} / \mathrm{z}:[\mathrm{M}+\mathrm{H}]^{+}, 313.26$. HRMS $\left(\mathrm{ESI}^{+}\right): \mathrm{m} / z=$ calcd for $\mathrm{C}_{19} \mathrm{H}_{25} \mathrm{~N}_{2} \mathrm{O}_{2}[\mathrm{M}+\mathrm{H}]^{+} 313.18377$ found: 313.18344 .

4.41. $\quad N^{1}$-[(8-Methoxy-1-methyl-2,3-dihydro-1H-cyclopenta[a]naphthalen-1-yl)methyl]-N ${ }^{3}$ propylurea (19d).

The crude product was recrystallized from toluene to afford $19 d(70 \%)$ as a white solid; mp 115-117 ${ }^{\circ} \mathrm{C} ;{ }^{1} \mathrm{H}$ NMR $\left(300 \mathrm{MHz}, \mathrm{DMSO}-d_{6}\right) \delta: 7.82(\mathrm{~d}, 1 \mathrm{H}, 9.0 \mathrm{~Hz}), 7.66(\mathrm{~d}, 1 \mathrm{H}, 8.1 \mathrm{~Hz})$, $7.40(\mathrm{~d}, 1 \mathrm{H}, 2.4 \mathrm{~Hz}), 7.20(\mathrm{~d}, 1 \mathrm{H}, 8.1 \mathrm{~Hz}), 7.09(\mathrm{dd}, 1 \mathrm{H}, 9.0 \mathrm{~Hz}$ and $2.4 \mathrm{~Hz}), 5.83($ br t, $1 \mathrm{H}$, $5.7 \mathrm{~Hz}$ ), 5.59 (br t, 1H, $6.0 \mathrm{~Hz}), 3.87(\mathrm{~s}, 3 \mathrm{H}), 3.71(\mathrm{dd}, 1 \mathrm{H}, 13.8 \mathrm{~Hz}$ and $6.0 \mathrm{~Hz}), 3.38$ (dd, 1H, $13.8 \mathrm{~Hz}$ and $6.0 \mathrm{~Hz}), 2.94-2.87(\mathrm{~m}, 4 \mathrm{H}), 2.23(\mathrm{~m}, 1 \mathrm{H}), 1.79(\mathrm{~m}, 1 \mathrm{H}), 1.46(\mathrm{~s}, 3 \mathrm{H}), 1.30$ (m 2H), $0.78(\mathrm{t}, 3 \mathrm{H}, 7.2 \mathrm{~Hz}) ;{ }^{13} \mathrm{C}$ NMR (75 MHz, DMSO-d $\left.{ }_{6}\right) \delta: 158.9,157.4,142.6,141.1$, $131.3,131.0,129.0,128.0,121.6,116.9,102.9,55.5,51.4,47.2,41.5,38.1,30.7,24.9,23.6$, 16.1; IR (v, $\left.\mathrm{cm}^{-1}\right): 3313(\mathrm{NH}), 1624(\mathrm{C}=\mathrm{O})$; LC-MS : m/z = $327\left(\mathrm{MH}^{+}\right)$. MS (APCI, pos. 30 V) m/z: $[\mathrm{M}+\mathrm{H}]^{+}$, 327.26. HRMS $\left(\mathrm{ESI}^{+}\right): \mathrm{m} / \mathrm{z}=$ calcd. for $\mathrm{C}_{20} \mathrm{H}_{27} \mathrm{~N}_{2} \mathrm{O}_{2}[\mathrm{M}+\mathrm{H}]^{+} 327.19942$ found: 327.19834 .

4.42. $N^{1}-\left[\left(8-m e t h o x y-2,3-d i h y d r o-1 H\right.\right.$-cyclopenta[a]naphthalen-1-yl)methyl]- $N^{3}$-methyl-thiourea $(\mathbf{1 7 k})$.

The crude product was purified by flash chromatography(cyclohexane/EtOAc : 5/5) and recrystallized from toluene to afford $\mathbf{1 7 k}(87 \%)$ as a white solid; mp $159-161{ }^{\circ} \mathrm{C} ;{ }^{1} \mathrm{H}$ NMR $\left(300 \mathrm{MHz}, \mathrm{CDCl}_{3}\right) \delta: 7.75(\mathrm{~d}, 1 \mathrm{H}, 9.0 \mathrm{~Hz}), 7.65(\mathrm{~d}, 1 \mathrm{H}, 8.1 \mathrm{~Hz}), 7.48(\mathrm{~s}, 1 \mathrm{H}), 7.26(\mathrm{~d}, 1 \mathrm{H}, 8.1$ Hz), $7.10(\mathrm{dd}, 1 \mathrm{H}, 9.0 \mathrm{~Hz}$ and $2.4 \mathrm{~Hz}), 5.90(\mathrm{br} \mathrm{s}, 2 \mathrm{H}), 4.23-4.04(\mathrm{~m}, 2 \mathrm{H}), 3.99$ (s, 3H), 3.53 $(\mathrm{m}, 1 \mathrm{H}), 3.20(\mathrm{~m}, 1 \mathrm{H}), 3.00(\mathrm{~m}, 1 \mathrm{H}), 2.83(\mathrm{~s}, 3 \mathrm{H}), 2.38(\mathrm{~m}, 1 \mathrm{H}), 2.14(\mathrm{~m}, 1 \mathrm{H}) ;{ }^{13} \mathrm{C}$ NMR $(75$ $\left.\mathrm{MHz}, \mathrm{CDCl}_{3}\right) \delta: 183.6,158.0,141.8,139.3,131.7,130.3,128.2,127.5,121.3,117.8,103.9$, 56.0, 46.4, 44.0, 31.4, 30.8, 28.8; IR (v, $\left.\mathrm{cm}^{-1}\right): 3392(\mathrm{NH}), 1213(\mathrm{C}=\mathrm{S})$; MS (APCI, pos. 30 V) m/z: $[\mathrm{M}+\mathrm{H}]^{+}, 301.26$. HRMS $\left(\mathrm{ESI}^{+}\right): \mathrm{m} / \mathrm{z}=$ calcd. for $\mathrm{C}_{17} \mathrm{H}_{21} \mathrm{~N}_{2} \mathrm{OS}[\mathrm{M}+\mathrm{H}]^{+} 301.13691$ found: 301.13648 . 
4.43. $\quad N^{1}$-Ethyl-N $N^{3}-[(8-m e t h o x y-2,3-$ dihydro-1H-cyclopenta[a]naphthalen-1-yl)methyl]thiourea (17).

The crude product was purified by flash chromatography (cyclohexane/EtOAc : 5/5) and recrystallized from toluene to afford $\mathbf{1 7 l}(64 \%)$ as a white solid; mp 200-202 ${ }^{\circ} \mathrm{C} ;{ }^{1} \mathrm{H}$ NMR (300 MHz, DMSO- $\left.d_{6}\right) \delta:$ 7.80-7.77 (m, 2H), $7.72($ br s, 1H), 7.65 (d, 1H, 8.4 Hz), 7.46 (s, 1H), $7.24(\mathrm{~d}, 1 \mathrm{H}, 8.4 \mathrm{~Hz}), 7.06(\mathrm{dd}, 1 \mathrm{H}, 9.0 \mathrm{~Hz}$ and $2.4 \mathrm{~Hz}), 4.09-3.98(\mathrm{~m}, 2 \mathrm{H}), 3.91(\mathrm{~s}, 3 \mathrm{H})$, $3.35(\mathrm{~m}, 2 \mathrm{H}), 3.20-2.86(\mathrm{~m}, 3 \mathrm{H}), 2.15-2.12(\mathrm{~m}, 2 \mathrm{H}), 1.08(\mathrm{t}, 3 \mathrm{H}, 6.9 \mathrm{~Hz}) ;{ }^{13} \mathrm{C} \mathrm{NMR}(75 \mathrm{MHz}$, DMSO- $\left.d_{6}\right) \delta: 182.6,158.0,141.8,139.3,131.7,130.3,128.2,127.5,121.3,117.8,103.8$, 56.0, 46.2, 44.0, 38.5, 31.4, 28.8, 14.9; IR (v, $\left.\mathrm{cm}^{-1}\right)$ : $3245(\mathrm{NH}), 1213(\mathrm{C}=\mathrm{S})$; MS (APCI, pos. $30 \mathrm{~V}) \mathrm{m} / \mathrm{z}:[\mathrm{M}+\mathrm{H}]^{+}, 315.22$. HRMS $\left(\mathrm{ESI}^{+}\right): \mathrm{m} / \mathrm{z}=$ calcd. for $\mathrm{C}_{18} \mathrm{H}_{23} \mathrm{~N}_{2} \mathrm{OS}[\mathrm{M}+\mathrm{H}]^{+} 315.19942$ found: 315.19834 .

4.44. $N^{1}$-[(8-Methoxy-2,3-dihydro-1H-cyclopenta[a]naphthalen-1-yl)methyl]-N ${ }^{3}$-propylthiourea $(\mathbf{1 7} \mathbf{m})$.

The crude product was recrystallized from toluene to afford $\mathbf{1 7} \mathbf{m}(56 \%)$ as a white solid; mp 137-139 ${ }^{\circ} \mathrm{C} ;{ }^{1} \mathrm{H}$ NMR (300 MHz, DMSO- $\left.d_{6}\right) \delta: 7.80-7.77(\mathrm{~m}, 2 \mathrm{H}), 7.73$ (br s, $\left.1 \mathrm{H}\right), 7.65$ (d, 1H, 8.1 Hz), $7.50(\mathrm{~s}, 1 \mathrm{H}), 7,24(\mathrm{~d}, 1 \mathrm{H}, 8.1 \mathrm{~Hz}), 7.07$ (dd, 1H, 9.0 Hz and 2.4 Hz), 4.15$3.98(\mathrm{~m}, 2 \mathrm{H}), 3.91(\mathrm{~s}, 3 \mathrm{H}), 3.33(\mathrm{~m}, 2 \mathrm{H}), 3.17-2.86(\mathrm{~m}, 3 \mathrm{H}), 2.15-2.11(\mathrm{~m}, 2 \mathrm{H}), 1.50(\mathrm{~m}, 2 \mathrm{H})$, $0.87(\mathrm{t}, 3 \mathrm{H}, 6.6 \mathrm{~Hz}) ;{ }^{13} \mathrm{C}$ NMR $\left(75 \mathrm{MHz}, \mathrm{DMSO}-d_{6}\right) \delta: 184.1,158.0,141.8,139.3,131.7$, $130.3,128.2,127.5,121.3,117.8,103.8,56.0,46.2,45.6,44.0,31.4,28.8,22.5,11.9$; IR (v,

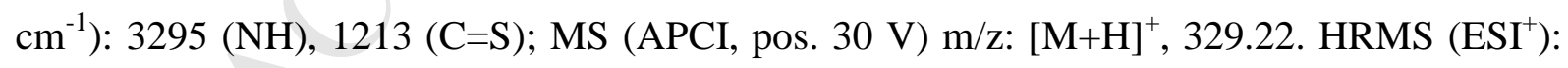
$m / z=$ calcd. for $\mathrm{C}_{19} \mathrm{H}_{25} \mathrm{~N}_{2} \mathrm{OS}[\mathrm{M}+\mathrm{H}]^{+} 329.16092$ found: 329.16034 .

4.45. $\quad N^{1}$-Methyl-N $N^{3}-[(8-m e t h o x y-1-m e t h y l-2,3-d i h y d r o-1 H$-cyclopenta[a]naphthalen-1-yl) methyl]thiourea (19e).

The crude product was recrystallized from toluene to afford 19e (57\%) as a white solid; mp 144-146 ${ }^{\circ} \mathrm{C} ;{ }^{1} \mathrm{H}$ NMR $\left(300 \mathrm{MHz}, \mathrm{DMSO}_{-}\right) \delta: 7.82(\mathrm{~d}, 1 \mathrm{H}, 9.0 \mathrm{~Hz}), 7.68(\mathrm{~d}, 1 \mathrm{H}, 8.2 \mathrm{~Hz})$, 
7.52 (d, 1H, $2.4 \mathrm{~Hz}$ ), 7.43 (br s, 1H), 7.22 (d, 1H, $8.2 \mathrm{~Hz}$ ), 7.19 (br s, 1H), 7.08 (dd, 1H, 9.0 $\mathrm{Hz}$ and $2.4 \mathrm{~Hz}), 4.41(\mathrm{~m}, 1 \mathrm{H}), 3.89(\mathrm{~s}, 3 \mathrm{H}), 3.61(\mathrm{~m}, 1 \mathrm{H}), 2.96-2.93(\mathrm{~m}, 2 \mathrm{H}), 2.82(\mathrm{~d}, 3 \mathrm{H}, 3.6$ $\mathrm{Hz}), 2.34(\mathrm{~m}, 1 \mathrm{H}), 1.80(\mathrm{~m}, 1 \mathrm{H}), 1.54(\mathrm{~s}, 3 \mathrm{H}) ;{ }^{13} \mathrm{C} \mathrm{NMR}\left(75 \mathrm{MHz}, \mathrm{DMSO}-d_{6}\right) \delta: 182.3,157.5$, $142.5,140.9,131.3,131.0,129.0,128.2,121.6,117.2,102.8,55.6,51.3,51.1,38.2,31.0$, 30.6, 24.7; IR (v, $\left.\mathrm{cm}^{-1}\right): 3297(\mathrm{NH}), 1212(\mathrm{C}=\mathrm{S})$; MS (APCI, pos. $\left.30 \mathrm{~V}\right) \mathrm{m} / \mathrm{z}:[\mathrm{M}+\mathrm{H}]^{+}$, 315.23. HRMS (ESI $\left.{ }^{+}\right): m / z=$ calcd. for $\mathrm{C}_{18} \mathrm{H}_{23} \mathrm{~N}_{2} \mathrm{OS}[\mathrm{M}+\mathrm{H}]^{+} 315.14528$ found: 315.14434 .

4.46. $\quad N^{1}$-Ethyl-N $N^{3}-[(8-m e t h o x y-1-m e t h y l-2,3-d i h y d r o-1 H$-cyclopenta[a]naphthalen-1-yl) methyl]thiourea (19f).

The crude product was recrystallized from toluene to afford $\mathbf{1 9 f}(51 \%)$ as a white solid; mp 125-127 ${ }^{\circ} \mathrm{C} ;{ }^{1} \mathrm{H}$ NMR $\left(300 \mathrm{MHz}, \mathrm{DMSO}-d_{6}\right) \delta: 7.2(\mathrm{~d}, 1 \mathrm{H}, 9.0 \mathrm{~Hz}), 7.67(\mathrm{~d}, 1 \mathrm{H}, 8.1 \mathrm{~Hz})$, $7.52(\mathrm{~d}, 1 \mathrm{H}, 2.4 \mathrm{~Hz}), 7.44$ (br s, 1H), $7.21(\mathrm{~d}, 1 \mathrm{H}, 8.1 \mathrm{~Hz}), 7.11-7.07$ (m, 2H), $4.44(\mathrm{~m}, 1 \mathrm{H})$, $3.90(\mathrm{~s}, 3 \mathrm{H}), 3.64(\mathrm{~m}, 1 \mathrm{H}), 3.36(\mathrm{q}, 2 \mathrm{H}, 7.5 \mathrm{~Hz}), 2.99-2.94(\mathrm{~m}, 2 \mathrm{H}), 2.33(\mathrm{~m}, 1 \mathrm{H}), 1.82(\mathrm{~m}$, 1H), $1.54(\mathrm{~s}, 3 \mathrm{H}), 1.03(\mathrm{t}, 3 \mathrm{H}, 7.5 \mathrm{~Hz}) ;{ }^{13} \mathrm{C} \mathrm{NMR}\left(75 \mathrm{MHz}, \mathrm{DMSO}-d_{6}\right) \delta: 183.7,157.5,142.6$, $140.8,131.3,131.0,129.0,128.2,121.6,117.2,102.7,55.6,51.2,51.0,38.8,38.2,30.7,24.8$, 14.8; IR (v, $\left.\mathrm{cm}^{-1}\right): 3294(\mathrm{NH}), 1223(\mathrm{C}=\mathrm{S})$; MS (APCI, pos. $\left.30 \mathrm{~V}\right) \mathrm{m} / \mathrm{z}:[\mathrm{M}+\mathrm{H}]^{+}, 329.27$. HRMS (ESI $\left.{ }^{+}\right): m / z=$ calcd. for $\mathrm{C}_{19} \mathrm{H}_{25} \mathrm{~N}_{2} \mathrm{OS}[\mathrm{M}+\mathrm{H}]^{+} 329.16094$ found: 329.16023 .

4.47. $\quad N^{1}$-[(8-Methoxy-1-methyl-2,3-dihydro-1H-cyclopenta[a]naphthalen-1-yl)methyl]-N ${ }^{3}$ propylthiourea $(\mathbf{1 9 g})$.

The crude product was recrystallized from toluene to afford $\mathbf{1 9 g}(41 \%)$ as a white solid; mp 109-111 ${ }^{\circ} \mathrm{C} ;{ }^{1} \mathrm{H}$ NMR $\left(300 \mathrm{MHz}, \mathrm{DMSO}-d_{6}\right) \delta: 7.82(\mathrm{~d}, 1 \mathrm{H}, 9.0 \mathrm{~Hz}), 7.67(\mathrm{~d}, 1 \mathrm{H}, 8.1 \mathrm{~Hz})$, 7.50-7.46 (m, 2H), $7.22(\mathrm{~d}, 1 \mathrm{H}, 8.1 \mathrm{~Hz}), 7.11-7.07(\mathrm{~m}, 2 \mathrm{H}), 4.43(\mathrm{~m}, 1 \mathrm{H}), 3.89(\mathrm{~s}, 3 \mathrm{H}), 3.63$ (m, 1H), $3.31(\mathrm{q}, 2 \mathrm{H}, 7.2 \mathrm{~Hz}), 2.98-2.95(\mathrm{~m}, 2 \mathrm{H}), 2.32(\mathrm{~m}, 1 \mathrm{H}), 1.80(\mathrm{~m}, 1 \mathrm{H}), 1.52(\mathrm{~s}, 3 \mathrm{H})$, $1.43(\mathrm{~m}, 2 \mathrm{H}), 0.82(\mathrm{t}, 3 \mathrm{H}, 7.2 \mathrm{~Hz}) ;{ }^{13} \mathrm{C} \mathrm{NMR}\left(75 \mathrm{MHz}, \mathrm{DMSO}-d_{6}\right) \delta: 182.6,157.5,142.6$, $140.8,131.3,131.0,129.0,128.3,121.6,117.2,102.7,55.6,51.2,51.1,45.4,38.2,30.7,24.8$, 
22.5, 11.8; IR (v, $\left.\mathrm{cm}^{-1}\right): 3213(\mathrm{NH}), 1223(\mathrm{C}=\mathrm{S})$; MS (APCI, pos. $\left.30 \mathrm{~V}\right) \mathrm{m} / \mathrm{z}:[\mathrm{M}+\mathrm{H}]^{+}$, 342.32. HRMS $\left(\mathrm{ESI}^{+}\right): m / z=$ calcd. for $\mathrm{C}_{20} \mathrm{H}_{27} \mathrm{~N}_{2} \mathrm{OS}[\mathrm{M}+\mathrm{H}]^{+} 342.17658$ found: 342.176223 . 4.48. (8-Methoxy-2,3-dihydro-1H-cyclopenta[a]naphthalen-1-yl)methylthiourea (17j).

To a solution of $17(0.50 \mathrm{~g}, 2,20 \mathrm{mmol})$ in a mixture of dioxane/THF (6/1) (35 mL) was added $12 \mathrm{M} \mathrm{HCl}(0.2 \mathrm{~mL})$ and potassium thiocyanate $(427 \mathrm{mg}, 4,40 \mathrm{mmol})$. The mixture was stirred at $60{ }^{\circ} \mathrm{C}$ during $16 \mathrm{~h}$ then hydrolyzed and extracted with EtOAc. The organic layer was washed with water, dried over $\mathrm{MgSO}_{4}$, filtered and concentrated under reduced pressure. The crude product was purified by flash chromatography (cyclohexane/ EtOAc : 5/5) to afford $\mathbf{1 7} \mathbf{j}$ (25\%) as a white solid; mp 86-87 ${ }^{\circ} \mathrm{C} ;{ }^{1} \mathrm{H}$ NMR (300 MHz, DMSO-d $)$ ) $\delta$ : 7.94 (br s, $\left.1 \mathrm{H}\right), 7.79$ (d, 1H, $9.0 \mathrm{~Hz}), 7.75$ (d, 1H, 2.4 Hz), 7.66 (d, 1H, 8.1 Hz), 7.24 (d, 1H, 8.1 Hz), 7.09 (dd, 1H, $9.0 \mathrm{~Hz}$ and $2.4 \mathrm{~Hz}), 7.04(\mathrm{br} \mathrm{s}, 2 \mathrm{H}), 4.00(\mathrm{~m}, 1 \mathrm{H}), 3.91$ (s, 3H), $3.60(\mathrm{~m}, 1 \mathrm{H}), 3.20-2.86(\mathrm{~m}$, $3 \mathrm{H}), 2.13-2.08(\mathrm{~m}, 2 \mathrm{H}) ;{ }^{13} \mathrm{C} \mathrm{NMR}\left(75 \mathrm{MHz}, \mathrm{DMSO}-d_{6}\right) \delta: 183.0,157.7,141.6,139.5,131.7$, 130.0, 128.1, 127.5, 121.3, 118.0, 102.1, 55.9, 46.3, 44.1, 31.3, 28.8; IR (v, $\left.\mathrm{cm}^{-1}, \mathrm{KBr}\right): 3291$ $(\mathrm{NH}), 1213(\mathrm{C}=\mathrm{S})$; MS (APCI, pos. $30 \mathrm{~V}) \mathrm{m} / \mathrm{z}:[\mathrm{M}+\mathrm{H}]^{+}, 287.22 . \mathrm{HRMS}\left(\mathrm{ESI}^{+}\right): \mathrm{m} / z=\mathrm{calcd}$. for $\mathrm{C}_{16} \mathrm{H}_{19} \mathrm{~N}_{2} \mathrm{OS}[\mathrm{M}+\mathrm{H}]^{+} 287.17658$ found: 287.176253 .

4.49. $\quad N^{1}-\left[\left(2-M e t h o x y-8,9-\right.\right.$ dihydro-7H-cyclopenta[h]quinolin-9-yl)methyl]-N$N^{3}$-methylurea (24b).

The crude product was purified by flash chromatography (cyclohexane/EtOAc : 5/5) and recrystallized from toluene to afford $\mathbf{2 4 b}(55 \%)$ as a white solid; mp $142-143{ }^{\circ} \mathrm{C} ;{ }^{1} \mathrm{H}$ NMR (300 MHz, $\left.\mathrm{CDCl}_{3}\right) \delta: 8.00(\mathrm{~d}, 1 \mathrm{H}, 8.9 \mathrm{~Hz}), 7.58(\mathrm{~d}, 1 \mathrm{H}, 7.7 \mathrm{~Hz}), 7.31(\mathrm{~d}, 1 \mathrm{H}, 7.7 \mathrm{~Hz})$, 6.87 (d, 1H, 8.9 Hz), 5.78 (br s, 1H), 4.25 (br s, 1H), 4.13 (s, 3H), 4.0 (m, 1H), $3.61(\mathrm{~m}, 2 \mathrm{H})$, $3.20(\mathrm{~m}, 1 \mathrm{H}), 3.00(\mathrm{~m}, 1 \mathrm{H}), 2.69(\mathrm{~d}, 2 \mathrm{H}, 4.3 \mathrm{~Hz}), 2.40(\mathrm{~m}, 1 \mathrm{H}), 2.10(\mathrm{~m}, 1 \mathrm{H}) ;{ }^{13} \mathrm{C} \mathrm{NMR}(75$ $\left.\mathrm{MHz}, \mathrm{CDCl}_{3}\right) \delta: 162.4,159.2,146.6,143.5,139.67,139.5,127.2,123.9,121.6,111.7,53.6$, 45.2, 43.6, 42.2, 32.3, 30.2, 27.1; IR $\left(v, \mathrm{~cm}^{-1}\right): 3290(\mathrm{NH}), 1626(\mathrm{C}=\mathrm{O})$; MS (APCI, pos. 30 
V) m/z: $[\mathrm{M}+\mathrm{H}]^{+}, 286.25$. HRMS $\left(\mathrm{ESI}^{+}\right): \mathrm{m} / \mathrm{z}=$ calcd. for $\mathrm{C}_{16} \mathrm{H}_{20} \mathrm{~N}_{3} \mathrm{O}_{2}[\mathrm{M}+\mathrm{H}]^{+} 286.155$ found: 286.15461 .

4.50. $\quad N^{l}-\left[\left(2-M e t h o x y-8,9-d i h y d r o-7 H\right.\right.$-cyclopenta[h]quinolin-9-yl)methyl]-N $N^{3}$-propylurea (24c).

The crude product was purified by flash chromatography (cyclohexane/EtOAc : 5/5) and recrystallized from toluene to afford $\mathbf{2 4 c}(78 \%)$ as a white solid; mp $167-168{ }^{\circ} \mathrm{C}$; ${ }^{1} \mathrm{H}$ NMR (300 MHz, $\left.\mathrm{CDCl}_{3}\right) \delta: 8.00(\mathrm{~d}, 1 \mathrm{H}, 8.8 \mathrm{~Hz}), 7.59$ (d, 1H, 8.3 Hz), 7.31 (d, 1H, $\left.8.3 \mathrm{~Hz}\right)$, $6.87(\mathrm{~d}, 1 \mathrm{H}, 8.8 \mathrm{~Hz}), 5.75$ (br t, 1H), 4.19 (br t, 1H), 4.13 (s, 3H), 4.0 (m, 1H), 3.63 (m, 2H), $3.35(\mathrm{~m}, 1 \mathrm{H}), 3.10-2.95(\mathrm{~m}, 3 \mathrm{H}), 2.40(\mathrm{~m}, 1 \mathrm{H}), 2.12(\mathrm{~m}, 1 \mathrm{H}), 1.41(\mathrm{q}, 2 \mathrm{H}, 7.5 \mathrm{~Hz}), 0.85(\mathrm{t}$, $3 \mathrm{H}, 7.53 \mathrm{~Hz}) ;{ }^{13} \mathrm{C} \mathrm{NMR}\left(75 \mathrm{MHz}, \mathrm{CDCl}_{3}\right) \delta: 162.4,158.5,146.6,143.6,139.5$ (2C), 127.2, 123.9, 121.6, 111.7, 53.6, 45.2, 43.6, 42.2, 32.3, 30.2, 23.4, 11.2; IR (v, $\left.\mathrm{cm}^{-1}\right): 3325(\mathrm{NH})$, $1613(\mathrm{C}=\mathrm{O})$; MS (APCI, pos. $30 \mathrm{~V}) \mathrm{m} / \mathrm{z}:[\mathrm{M}+\mathrm{H}]^{+}, 314.35$. HRMS $\left(\mathrm{ESI}^{+}\right): \mathrm{m} / z=$ calcd. for $\mathrm{C}_{18} \mathrm{H}_{24} \mathrm{~N}_{3} \mathrm{O}_{2}[\mathrm{M}+\mathrm{H}]^{+}$313.17902 found 313.17743.

\section{Pharmacological methods}

\subsection{Reagents and Chemicals.}

$2-\left[{ }^{125} \mathrm{I}\right]$-Iodomelatonin $(2200 \mathrm{Ci} / \mathrm{mmol})$ was purchased from NEN (Boston, MA). Other drugs and chemicals were purchased from Sigma-Aldrich (Saint Quentin, France).

\subsection{Cell Culture.}

HEK (provided by A.D. Strosberg, Paris, France) and CHO cell lines stably expressing the human melatonin $\mathrm{MT}_{1}$ or $\mathrm{MT}_{2}$ receptors were grown in DMEM medium supplemented with $10 \%$ fetal calf serum, $2 \mathrm{mM}$ glutamine, $100 \mathrm{IU} / \mathrm{mL}$ penicillin and $100 \mu \mathrm{g} / \mathrm{ml}$ streptomycin. Grown at confluence at $37{ }^{\circ} \mathrm{C}\left(95 \% \mathrm{O}_{2} / 5 \% \mathrm{CO}_{2}\right)$, they were harvested in PBS containing EDTA $2 \mathrm{mM}$ and centrifuged at $1000 \mathrm{x}$ g for $5 \mathrm{~min}\left(4^{\circ} \mathrm{C}\right)$. The resulting pellet was suspended in TRIS $5 \mathrm{mM}(\mathrm{pH} 7.5)$, containing EDTA $2 \mathrm{mM}$ and homogenized using a 
Kinematica polytron. The homogenate was then centrifuged $\left(95000 \mathrm{~g}, 30 \mathrm{~min}, 4^{\circ} \mathrm{C}\right)$ and the resulting pellet suspended in $75 \mathrm{mM}$ TRIS ( $\mathrm{pH} 7.5$ ), $12.5 \mathrm{mM} \mathrm{MgCl}_{2}$ and $2 \mathrm{mM}$ EDTA. Aliquots of membrane preparations were stored at $-80{ }^{\circ} \mathrm{C}$ until use.

\subsection{Binding Assays.}

$2-\left[{ }^{125} \mathrm{I}\right]$ iodomelatonin binding assay conditions were essentially as previously described [27]. Briefly, binding was initiated by addition of membrane preparations from stable transfected HEK or CHO cells diluted in binding buffer $(50 \mathrm{mM}$ Tris- $\mathrm{HCl}$ buffer, $\mathrm{pH} 7.4$ containing $5 \mathrm{mM} \mathrm{MgCl}_{2}$ ) to 2-[ $\left.{ }^{125} \mathrm{I}\right]$-iodomelatonin (25 or $200 \mathrm{pM}$ for $\mathrm{MT}_{1}$ and $\mathrm{MT}_{2}$ receptors, respectively, expressed in HEK cells or $20 \mathrm{pM}$ for $\mathrm{MT}_{1}$ and $\mathrm{MT}_{2}$ receptors expressed in $\mathrm{CHO}$ cells) and the tested drug. Nonspecific binding was defined in the presence of $1 \mu \mathrm{M}$ melatonin. After $120 \mathrm{~min}$ incubation at $37^{\circ} \mathrm{C}$, reaction was stopped by rapid filtration through GF/B filters presoaked in $0.5 \%(\mathrm{v} / \mathrm{v})$ polyethylenimine. Filters were washed three times with $1 \mathrm{ml}$ of ice-cold $50 \mathrm{mM}$ Tris-HCl buffer, $\mathrm{pH}$ 7.4.

Data from the dose-response curves ( 7 concentrations in duplicate) were analysed using PRISM program (Graph Pad Software Inc., San Diego, CA) to yield $\mathrm{IC}_{50}$ (inhibitory concentration 50). Results are expressed as $\mathrm{K}_{\mathrm{i}}=\mathrm{IC}_{50} / 1+\left([\mathrm{L}] / \mathrm{K}_{\mathrm{D}}\right)$, where [L] is the concentration of radioligand used in the assay and $\mathrm{K}_{\mathrm{D}}$, the dissociation constant of the radioligand characterising the membrane preparation [28].

$\left[{ }^{35} \mathrm{~S}\right] \mathrm{GTP} \gamma \mathrm{S}$ binding assay was performed according to published methodology [27]. Briefly, membranes from transfected $\mathrm{CHO}$ cells expressing $\mathrm{MT}_{1}$ or $\mathrm{MT}_{2}$ receptor subtype and compounds were diluted in binding buffer (20 mM HEPES, pH 7.4, $100 \mathrm{mM} \mathrm{NaCl}, 3 \mu \mathrm{M}$ GDP, $3 \mathrm{mM} \mathrm{MgCl}$, and $20 \mu \mathrm{g} / \mathrm{mL}$ saponin). Incubation was started by the addition of $0.2 \mathrm{nM}$ $\left[{ }^{35} \mathrm{~S}\right] \mathrm{GTP} \gamma \mathrm{S}$ to membranes $(20 \mu \mathrm{g} / \mathrm{ml})$ and drugs, and further followed for $1 \mathrm{~h}$ at room temperature. For experiments with antagonists, membranes were pre-incubated with both the melatonin $(3 \mathrm{nM})$ and the antagonist for $30 \mathrm{~min}$ prior the addition of $\left[{ }^{35} \mathrm{~S}\right] \mathrm{GTP} \gamma \mathrm{S}$. Non 
specific binding was defined using cold GTP $\gamma \mathrm{S}(10 \mu \mathrm{M})$. Reaction was stopped by rapid filtration through GF/B filters followed by three successive washes with ice cold buffer.

Usual levels of $\left[{ }^{35} \mathrm{~S}\right] \mathrm{GTP} \gamma \mathrm{s}$ binding (expressed in dpm) were for $\mathrm{CHO}-\mathrm{MT}_{1}$ or $\mathrm{MT}_{2}$ membranes: 2000 for basal activity, 8000 in the presence of melatonin $1 \mu \mathrm{M}$ and 180 in the presence of GTP $\gamma \mathrm{S} 10 \mu \mathrm{M}$ which defined the non specific binding. Data from the doseresponse curves ( 7 concentrations in duplicate) were analyzed by using the program PRISM (Graph Pad Software Inc., San Diego, CA) to yield EC 50 (Effective concentration $50 \%$ ) and $\mathrm{E}_{\max }$ (maximal effect) for agonists. Antagonist potencies are expressed as $\mathrm{K}_{\mathrm{B}}=\mathrm{IC}_{50} / 1+$ ([Ago]/EC $\mathrm{E}_{50}$ ago), where $\mathrm{IC}_{50}$ is the inhibitory concentration of antagonist that gives $50 \%$ inhibition of $\left[{ }^{35} \mathrm{~S}\right] \mathrm{GTP} \gamma \mathrm{S}$ binding in the presence of a fixed concentration of melatonin ([Ago]) and $\mathrm{EC}_{50}$ ago is the $\mathrm{EC}_{50}$ of the molecule when tested alone. $\mathrm{I}_{\max }$ (maximal inhibitory effect) was expressed as a percentage of that observed with melatonin at $3 \mathrm{nM}$ for $\mathrm{MT}_{2}$ receptor.

Serotonin 5-HT $2 \mathrm{C}$ binding assay was determined according to reported tests [29]. First incubation of $200 \mu \mathrm{l}$ solution from membrane $\mathrm{CHO}$ cell lines, stably expressing the human 5$\mathrm{HT}_{2 \mathrm{C}}$ receptors, for $60 \mathrm{~min}$ at $37{ }^{\circ} \mathrm{C}$ in binding buffer $(50 \mathrm{mM}$ Tris- $\mathrm{HCl}$ buffer, $\mathrm{pH} 7.4$, containing $10 \mathrm{mM} \mathrm{MgCl} 2$ and $0.1 \%$ BSA) containing the radioligand $\left[{ }^{3} \mathrm{H}\right]$-mesulergine (1 $\mathrm{nM})$. Non-specific binding was defined in the presence of $10 \mu \mathrm{M}$ mianserine. Dose-response curves are obtained by displacement of the radioligand. Reaction was stopped by rapid filtration through GF/B filters presoaked in $0.1 \%(\mathrm{v} / \mathrm{v})$ polyethylenimine. Filters were washed three times with $1 \mathrm{~mL}$ of ice-cold $50 \mathrm{mM}$ Tris-HCl buffer, $\mathrm{pH}$ 7.4. Residual radioactivity was revealed by addition of Microscint 20 and measured by using TopCount calculator (Packard). $\mathrm{IC}_{50}$ was determined from dose-response curves and results are expressed as $\mathrm{K}_{\mathrm{i}}=\mathrm{IC}_{50} / 1+$ $([\mathrm{L}] / \mathrm{KD})$, where $[\mathrm{L}]$ is the concentration of radioligand used in the assay and $\mathrm{KD}$, the dissociation constant of the radioligand characterising the membrane preparation. 


\section{Acknowledgement}

The authors would like to acknowledge the Region Hauts de France (France), the Ministère de la Jeunesse, de l'Education Nationale et de la Recherche (MJENR) and the Fonds Européens de Développement Régional (FEDER) for funds allowed for NMR facilities.

\section{References}

[1] A.B. Lerner, J.D. Case, Y. Takahashi, T.J. Lee, W. Mori, Isolation of melatonin, the pineal gland factor that lightens melanocytes, J. Am. Chem. Soc. 80 (1958) 2587-2588.

[2] J. Vanecek, Cellular mechanisms of melatonin action, Physiol. Rev. 78 (1998) 687-721.

[3] (a) J.R. Calvo, C. Gonzalez-Yanes, M.D. Maldonado, The role of melatonin in the cells of the innate immunity: A review, J. Pineal Res. 55 (2013) 103-120. (b) A; Cagnacci, K. Krauchi, A. Wirz-Justice, A. Volpe, Homeostatic versus circadian effects of melatonin on core body temperature in humans, J. Biol. Rhythm. 12 (1997) 509-517.

[4] (a) G. Favero, L. Franceschetti, B. Buffoli, M.H. Moghadasian, R.J. Reiter, L.F. Rodella, R. Rezzani, Melatonin: Protection against age-related cardiac pathology, Ageing Res. Rev. 35 (2016) 336-349. (b) J. Falcon, L. Besseau, D. Fazzari, J. Attia, P. Gaildrat, M. Beauchaud, G. Boeuf, Melatonin modulates secretion of growth hormone and prolactin by trout pituitary glands and cells in culture, Endocrinology 144 (2003) 4648-4658.

[5] (a) S.C Su, M.J. Hsieh, W.E. Yang, W.H. Chung, R.J. Reiter, S.F. Yang, Cancer metastasis: Mechanisms of inhibition by melatonin, J. Pineal Res. 62 (2017) doi: 10.1111/jpi.12370. (b) V. Srinivasan, E.C. Lauterbach, K.Y. Ho, D. AcunaCastroviejo, R. Zakaria, A. Brzezinski, Melatonin in antinociception: Its therapeutic applications, Curr. Neuropharmacol. 10 (2012) 167-178. (c) S.P. Fisher, K. Davidson, 
A. Kulla, D. Sugden, Acute sleep-promoting action of the melatonin agonist, ramelteon, in the rat, J. Pineal Res. 45 (2008) 125-132.

[6] (a) J.A. Boutin, Quinone reductase 2 as a promising target of melatonin therapeutic actions, Expert Opin. Ther. Targets 20 (2016) 303-317. (b) V. Lyssenko, C.L. Nagorny, M.R. Erdos, N. Wierup, A. Jonsson, P. Spegel, M. Bugliani, R. Saxena, M. Fex, N. Pulizzi, B. Isomaa, T. Tuomi, P. Nilsson, J. Kuusisto, J. Tuomilehto, M. Boehnke, D. Altshuler, F. Sundler, J.G. Eriksson, A.U. Jackson, M. Laakso, P. Marchetti, R.M. Watanabe, H. Mulder, L. Groop, Common variant in MTNR1B associated with increased risk of type 2 diabetes and impaired early insulin secretion, Nat. Genet. 41 (2009) 82-88.

[7] (a) L. Lanfumey, R. Mongeau, M. Hamon, Biological rhythms and melatonin in mood disorders and their treatments, Pharmacol. Ther. 138 (2013) 176-184. (b) J.Z. Wang, Z.F. Wang, Role of melatonin in Alzheimer-like neurodegeneration, Acta Pharmacol. Sin. 27 (2006) 41-49. (c) D. De Berardis, I.G. Di, T. Acciavatti, C. Conti, N. Serroni, L. Olivieri, M. Cavuto, G. Martinotti, L. Janiri, F.S. Moschetta, P. Conti, M. Di Giannantonio, The emerging role of melatonin agonists in the treatment of major depression: Focus on agomelatine, CNS Neurol. Disord. Drug Targets 10 (2011) 119132.

[8] F.C. Koyama, R.Y. Ribeiro, J.L. Garcia, M.F. Azevedo, D. Chakrabarti, C.R. Garcia, Ubiquitin proteasome system and the atypical kinase PfPK7 are involved in melatonin signaling in Plasmodium falciparum. J. Pineal Res. 53 (2012) 147-153.

[9] (a) W.R. Lima , A.A. Holder, C.R.S. Garcia, Melatonin Signaling and Its Modulation of PfNF-YB Transcription Factor Expression in Plasmodium falciparum. Int. J. Mol. Sci. 14 (2013) 13704-13718. (b) V. Srinivasan, M. Mohamed, R. Zakaria, A.H. Ahmad, 
Malaria, anti malarial drugs and the role of melatonin. Infect. Disord. Drug Targets 12 (2012) 371-379.

[10] (a) V. Srinivasan, R. Zakaria, M. Mohamed, R.M. Saleh, Effects of melatonin derivatives on human malaria parasite Plasmodium falciparum. Recent Pat. Endocr. Metab. Immune Drug Discov. 8 (2014) 102-108. (b) D.C. Schuck, A.K. Jodão, M. Nakabashi, A.C. Cunha, V.F. Ferreira, C.R. Garcia, Synthetic indole and melatonin derivatives exhibit antimalarial activity on the cell cycle of the human malaria parasite Plasmodium falciparum. Eur. J. Med. Chem. 78 (2014) 375-382.

[11] (a) E.K. Elmahallawy, J.O. Lugue, A.S. Aloweidi, J. Guttiérrez-Fernàndez, A. Sampedro-Martinez, J. Rodriguez-Granger, A. Kaki, A. Agil, Potential Relevance of Melatonin Against Some Infectious Agents: A Review and Assessment of Recent Research. Curr. Med. Chem. 22 (2015) 3848-3861. (b) L.G. Oliveira, C.C. Kuehn, C.D. dos Santos, M.A. Miranda, C.M. da Costa, V.J. Mendonca, J.C. do Prado Jùnior, Protective actions of melatonin against heart damage during chronic Chagas disease. Acta Trop. 128 (2013) 652-658.

[12] (a) M.L. Dubocovich, M. Markowska, Functional $\mathrm{MT}_{1}$ and $\mathrm{MT}_{2}$ melatonin receptors in mammals, Endocrine 27 (2005) 101-110. (b) J.A. Boutin, A. Bonnaud, C. Brasseur, O. Bruno, N. Lepretre, P. Oosting, S. Coumailleau, P. Delagrange, O. Nosjean, C. Legro, New $\mathrm{MT}_{2}$ Melatonin Receptor-Selective Ligands: Agonists and Partial Agonists, Int. J. Mol. Sci. 18 (2017) 1347.

[13] (a) K. Hirai, K. Kato, H. Nishikawa, N. Yukuhiro, K. Nishiyama, M. Miyamoto, Preclinical pharmacological profiles and clinical outcome of the novel melatoninreceptor agonist ramelteon (Rozerem 8 mg), Nihon Yakurigaku Zasshi 136 (2010) 5160. (b) S. Dhillon, M. Clarke, Tasimelteon: First global approval, Drugs 74 (2014) 505- 
511. (c) P. Lemoine, N. Zisapel, Prolonged-release formulation of melatonin (Circadin) for the treatment of insomnia, Expert Opin. Pharmacother. 13 (2012) 895-905.

[14] C. De Bodinat, B. Guardiola-Lemaitre, E. Mocaer, P. Renard, C. Munoz, M.J. Millan, Agomelatine, the first melatonergic antidepressant: Discovery, characterization and development, Nat. Rev. Drug Discov. 9 (2010) 628-642.

[15] R.H. McAllister-Williams, D.S. Baldwin, P.M. Haddad, S. Bazire, The use of antidepressants in clinical practice: focus on agomelatine, Hum. Psychopharmacol. Clin. Exp. 25 (2010) 95-102.

[16] B. Guardiola-Lemaitre, C. De Bodinat, P. Delagrange, M.J. Millan, C. Munoz, E. Mocaër, Agomelatine: mechanism of action and pharmacological profile in relation to antidepressant properties, B. J. Pharmacol. 171 (2014) 3604-3619.

[17] (a) M. Ettaoussi, A. Sabaouni, M. Rami, J.A. Boutin, P. Delagrange, P. Renard, M. Spedding, D.H. Caignard, P. Berthelot, S. Yous, Design, synthesis and pharmacological evaluation of new series of naphthalenic analogues as melatoninergic $\left(\mathrm{MT}_{1} / \mathrm{MT}_{2}\right)$ and serotoninergic 5-HT $2 \mathrm{C}$ dual ligands (I), Eur. J. Med. Chem. 49 (2012) 310-323. (b) M. Ettaoussi, B. Pérès, A. Errazani, J.A. Boutin, D.H. Caignard, P. Delagrange, P. Melnyk, P. Berthelot, S. Yous, Synthesis and pharmacological evaluation of dual ligands for melatonin $\left(\mathrm{MT}_{1} / \mathrm{MT}_{2}\right)$ and serotonin 5-HT $2 \mathrm{C}$ receptor subtypes (II), Eur. J. Med. Chem. $90(2015) 822-833$.

[18] M. Ettaoussi, A. Sabaouni, B. Pérès, E. Landagaray, O. Nosjean, J.A. Boutin, D.H. Caignard, P. Delagrange, P. Berthelot, S. Yous, Synthesis and pharmacological evaluation of a series of the agomelatine analogues as melatonin $\mathrm{MT}_{1} / \mathrm{MT}_{2}$ agonist and 5-HT $2 \mathrm{C}$ antagonist. ChemMedChem. 8 (2013) 1830-1845.

[19] E. Landagaray, M. Ettaoussi, V. Leclerc, B. Traor_e, V. Perez, O. Nosjean, J.A. Boutin, D.H. Caignard, P. Delagrange, P. Berthelot, S. Yous, New melatonin $\left(\mathrm{MT}_{1} / \mathrm{MT}_{2}\right)$ 
ligands: design and synthesis of (8,9-dihydro-7H-furo[3,2-f] chromen-1-yl) derivatives, Bioorg. Med. Chem. 22 (2014) 986-996.

[20] E. Landagaray, M. Ettaoussi, R. Duroux, J.A. Boutin, D.H. Caignard, P. Delagrange, P. Melnyk, P. Berthelot, S. Yous, Melatonergic ligands: Design, synthesis and pharmacological evaluation of novel series of naphthofuranic derivatives, Eur. J. Med. Chem. 109 (2016) 360-370.

[21] Y. Miyamoto, Y. Banno, T. Yamashita, T. Fujimoto, S. Oi, Y. Moritoh, T. Asakawa, O. Kataoka, H. Yashiro, K. Takeuchi, N. Suzuki, K. Ikedo, T. Kosaka, S. Tsubotani, A. Tani, M. Sasaki, M. Funami, M. Amano, Y. Yamamoto, K. Aertgeerts, J. Yano, H. Maezaki, Discovery of a 3-Pyridylacetic Acid Derivative (TAK-100) as a Potent, Selective and Orally Active Dipeptidyl Peptidase IV (DPP-4) Inhibitor, J. Med. Chem. 54 (2011) 831-850.

[22] W.E. Bauta, D.P. Lovett, W.R. Cantrell, B.D. Burke, Formal Synthesis of Angiogenesis Inhibitor NM-3, J. Org. Chem. 68 (2003) 5967-5973.

[23] A.K. Sharma Amutha, V.S. Christopher, B. Gorman, Efficient synthesis of halo indanone via chlorosulfonic acid mediated Friedel-Craft cyclisation of aryl propionic acids and their use in alkylation reactions, Tetrahedron 63 (2007) 389-395.

[24] K. Fukatsu, O. Uchikawa, M. Kawada, T. Yamano, M. Yamashita, K.Kato, K. Hirai, S. Hinuma, M. Miyamoto, S. Ohkawa, Synthesis of a Novel Series of Benzocycloalkene Derivatives as Melatonin Receptor Agonists, J. Med. Chem. 45 (2002) 4212-4221.

[25] T. Koike, Y. Hoashi, T. Takai, M. Nakayama, N. Yukuhiro, T. Ishikawa, K. O. Uchikawa, 1,6-Dihydro-2H-indeno[5,4-b]furan derivatives: design, synthesis, and pharmacological characterization of a novel class of highly potent $\mathrm{MT}_{2}$-selective agonists, J. Med. Chem. 54 (2011) 3436-3444.

[26] U.H. Lindberg, B. Nylen, B. Akerman, Potential local anaesthetics. I. Basic N-(alpha- 
cycloalkylbenzyl)-acylamides and some related compounds. Acta Pharm. Suec. 5 (1968) 429-440.

[27] V. Audinot, F. Mailliet, C. Lahaye-Brasseur, A. Bonnaud, A. Le Gall, A. Amossé, C. Dromaint, S. Rodriguez, N. Nagel, J.P. Galizzi, B.. Malpaux, G. Guillaumet, D. Lesieur, F. Lefoulon, P. Renard, P. Delagrange, J.A. Boutin, Naunyn-Schmiedeberg's Arch. Pharmacol. 367 (2003) 553-561.

[28] Cheng, Y. and Prusoff, W.H. Relationship between the inhibition constant (K1) and the concentration of inhibitor which causes 50 per cent inhibition (I50) of an enzymatic reaction. Biochem. Pharmacol. 22 (1973) 3099-3108.

[29] R.S. Westphal and E. Sanders-Bush, Reciprocal binding properties of 5hydroxytryptamine type $2 \mathrm{C}$ receptor agonists and inverse agonists. Mol. Pharmacol. 46 (1994) 937-942. 


\section{HIGHLIGHTS}

- New constrained analogues of agomelatine were designed and synthesized

- Prepared compounds showed good affinities at melatonin and $5 \mathrm{HT}_{2 \mathrm{C}}$ receptors

- Naphthocyclopentane derivative 17a was considered as the lead

- (-)-17k represents one of the highest dual MT and $5 \mathrm{HT}_{2 \mathrm{C}}$ derivative 